\title{
Market Dynamics and Indirect Network Effects in Electric Vehicle Diffusion ${ }^{\text {th }}$
}

\author{
Zhe Yu ${ }^{\mathrm{a}}$, Shanjun $\mathrm{Li}^{\mathrm{b}, *}$, Lang Tong ${ }^{\mathrm{a}}$ \\ ${ }^{a}$ School of Electrical and Computer Engineering, Cornell University, Ithaca, NY 14853, USA. \\ ${ }^{b}$ Dyson School of Applied Economics $\mathcal{E}$ Management, Cornell University, Ithaca, NY 14853, USA.
}

\begin{abstract}
The diffusion of electric vehicles (EVs) is studied in a two-sided market framework consisting of EVs on the one side and EV charging stations (EVCSs) on the other. A sequential game is introduced as a model for the interactions between an EVCS investor and EV consumers. A consumer chooses to purchase an EV or a conventional gasoline alternative based on the upfront costs of purchase, the future operating costs, and the availability of charging stations. The investor, on the other hand, maximizes his profit by deciding whether to build charging facilities at a set of potential EVCS sites or to defer his investments.

The solution of the sequential game characterizes the EV-EVCS market equilibrium. The market solution is compared with that of a social planner who invests in EVCSs with the goal of maximizing the social welfare. It is shown that the market solution underinvests EVCSs, leading to slower EV diffusion. The effects of subsidies for EV purchase and EVCSs are also considered.

Keywords: Two-sided market; indirect network effects; product diffusion; electric vehicles; EV charging services
\end{abstract}

\section{Introduction}

The electrification of the transportation sector through the diffusion of plug-in electric vehicles (EVs), coupled with cleaner electricity generation, is considered a promising pathway to reduce air pollution from on-road vehicles and to strengthen energy security. However, the diffusion of electric vehicles in the United States has had mixed results so far. Annual new EV sales increased nearly 7-fold from about 18,000 in 2011 to 116, 100 in 2015. Yet, the market share of EVs was only about $0.73 \%$ in the new vehicle market by 2014 (Hybridcars, 2014).

A similar trend exists in the deployment of public charging services. The U.S. has built about 9900 charging stations with about 26000 charging outlets (U.S. Department of Energy, 2015), due in part to the direct and indirect investments of federal and local governments. For example, the Department of Energy (DoE) provided 230 million dollars from 2013 to establish 13,000 charging stations (Electric Transportation Engineering Corporation, 2013). It has been hoped

\footnotetext{
${ }^{*}$ Corresponding author

Email addresses: zy73@cornell. edu (Zhe Yu), s12448@cornell.edu (Shanjun Li), 1t35@cornell.edu (Lang Tong)
} 
that such investments will stimulate the EV market, driving its market share toward long-term growth and stability.

The growth trends of EVs and EVCSs have strong temporal and geographic couplings as shown in Fig. 11 This is the "cluster" phenomenon of alternative fuel vehicles discussed in (Winebrake and Farrell, 1997), which is the first article to discuss the network effects between the alternative fuel vehicles and the fueling infrastructure. Consumers' EV adoption in the EV market is affected by the availability of EV charging stations whereas the level of EVCS investment strongly depends on the size of EV stock. Thus areas with a lower cost to adopt charging stations will attract more EVs and more EVs incentivize the investors to build more charging stations.

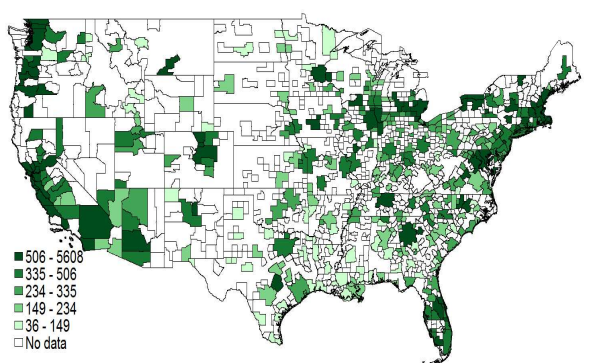

(a) EV stock per million people.

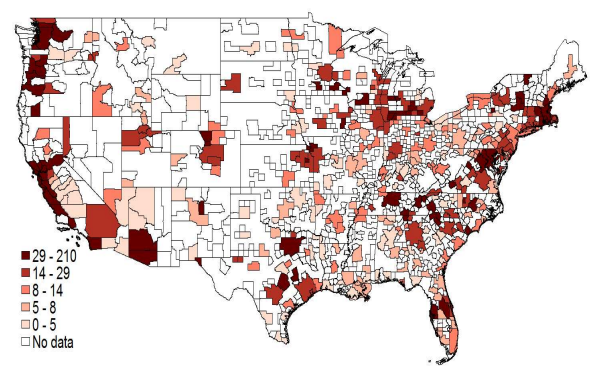

(b) Public charging stations per million people.

Figure 1: EVs and public charging stations in Metropolitan Statistical Areas in 2014 (Hybridcars, 2014).

The reason behind the growth of the EV market, or the lack of it, is multifaceted. The growth is driven partially by the increasing awareness of the environmental impacts of gasoline vehicles, superior designs and performance of some EVs, and, by no small measure, subsidies in the form of tax credits provided by the federal and state governments. However, the EV industry faces stiff skepticism due to the high purchase cost of EVs, the limited driving range, the long charging time, and the lack of public charging facilities.

The manufacturer's suggested retail price (MSRP) of the 2016 Nissan Leaf, Ford Focus Electric, and Chevrolet Volt are \$34200, \$29170, and \$25670, respectively, which are more than $\$ 10000$ above the purchase price of comparable gasoline vehicles, such as Nissan Sentra, Ford Focus, and Chevrolet Cruze. To make EVs equally attractive as internal-combustion vehicles, federal and state governments provide a tax credit subsidy up to $\$ 7500$ for each purchase of EVs. Meanwhile, the cost of electric vehicle batteries, which is the major cost of electric vehicles, has been reduced by more than $65 \%$ since 2010 . It is projected that, by 2020 , EVs will become more economic than internal-combustion vehicles even without government subsidies (Bloomberg New Energy Finance, 2016). Besides the quick drop of the battery cost, the low operation cost of EVs also significantly offsets the high capital cost (Electric Power Reserach Institute, 2013).

The limited driving range of EVs, however, restricts the adoption significantly. By 2016, Nissan Leaf has an range of 107 miles after a full charge, comparing with the range of 99 miles of Ford Focus Electric and 53 electric miles of Chevrolet Volt. While the gasoline vehicles can easily achieve a driving range of over 400 miles per tank of gas. The anxiety of running out of electricity makes the EV charging infrastructure and charging time important considerations 
when consumers choose vehicles.

There are typically three levels of charging rate, among which Level 1 is used as residential charging choice, and Level 2 and DC fast charge (DCFC) are usually used as public charging stations. The use of higher level charging rate will dramatically reduce the charging time. But the building cost of high level charging stations are also significantly higher.

Level 1 provides charging from a standard residential 120 volt AC outlet. Overnight charging can replenish about 40 miles of driving range. However, a completely depleted battery could take up to 20-22 hours to completely recharge. Level 2 uses $240 \mathrm{~V}$ residential or $208 \mathrm{~V}$ commercial AC power, which will supply up to approximately 15 miles of travel for one hour of charging to vehicles with a $3.3 \mathrm{~kW}$ onboard charger, or 30 miles of travel for one hour of charging for vehicles with a $6.6 \mathrm{~kW}$ onboard charger. To fully charge an EV, it would take around 7 hours. Level 2 equipment needs a dedicated electrical circuit to improve safety thus requires professional electrical installation. The cost of installing a single port in a residential house is a little bit more than $\$ 1000$, over half of which is the hardware cost (Josh Agenbroad and Ben Holland, 2014). The cost of installing a level 2 charging station in public stations, which is the dominant charging rate nowadays, varies from $\$ 2,000$ to $\$ 15,000$ with the number of ports, station features and brands. DC fast charging requires commercial grade $480 \mathrm{~V} \mathrm{AC} \mathrm{power} \mathrm{circuite} \mathrm{so} \mathrm{it} \mathrm{is} \mathrm{only}$ available in public charging stations. DCFC transforms the AC power to DC and supplies up to 40 miles of range of driving for every 10 minutes of charging, or fully recharge in 30 minutes. The cost of a DC charging station is between $\$ 50,000$ to $\$ 100,000$ due to the expensive hardware and the frequent need to install a $480 \mathrm{~V}$ transformer. When traveling long distance using EVs, public charging stations are necessary to reduce the anxiety of the lack of electricity. Comparing to the gasoline vehicles, the charging time of EVs is significant long and requires more public charging stations, even considering the option of charging at home.

There are several major parties who invest in EV charging stations. The government invests in charging stations in public facilities such as hospitals and schools due to the environmental consideration. The business runners of grocery stores and shopping malls build charging stations near their business to attract customers for the main business, provide a bonus service for employees, and boost the sustainability credentials. The national major operators of charging stations, such as ChargePoint and eVgo, invest in charging service targeting the rapid growing EV market. The manufactories of EVs build charging stations to boost the market share of their products and provide after sales services to loyal consumers. However, the amount of EV charging stations is far from sufficient, mainly due to the small amount of ownership of EVs.

\subsection{Summary of results}

The main contribution of this work is to provide an analytical study on indirect network effects in the EV market. In particular, we formulate a sequential game for the two-sided market and address analytically and numerically the following questions: how does the EV adoption interact with EVCS investment? How do indirect network effects affect market dynamics? What are the implications of indirect network effects on the public policy?

We introduce a perfect and complete sequential game model for the two-sided EV-EVCS market with an investor as the leader and each consumer a follower. Through profit maximization, the investor decides whether to build EVCSs at sites chosen (optimally) from a list of

\footnotetext{
${ }^{1}$ Level 1, 2, and DCFC are the mostly widely deployed classes of chargers. For the information of other classes, the information can be found at: http://standards.sae.org/j2836/2_201109/
} 
candidate sites or to defer his investment with earned interest. The candidate sites are heterogeneous; each site may have a different favorability rating and different capital costs. The optimal investment decision also includes the optimal pricing of charging services.

Observing investor's decision which defines the locations of EVCSs and the charging prices, a consumer decides whether to purchase an EV or a gasoline alternative. If the choice is an EV, the consumer also decides the preferred charging service.

We provide a solution to the sequential game that includes the optimal decisions for the consumers and the investor. A random utility maximization (RUM) model (Marschak, 1960) with two different distributions of the consumer vehicle preference is considered.

Under the assumption that the consumer vehicle preference has the type I extreme value distribution, we show that the optimal purchasing decision is a threshold policy on the difference of vehicle preferences of the consumer. A closed-form expression for the EV market share $\eta_{e}$ is obtained, where $\eta_{e}$ is a function of the EV purchasing price, the investor's decisions on the number/locations of charging stations, and the charging prices at those locations. The obtained closed-form solution allows us to examine how the investor's decisions and the cost of EVs affect the overall EV market share.

To obtain the optimal investment decision, we first study the optimal operation decision of the investor by fixing the set of EVCS sites. We show that the optimal pricing for EV charging at these sites is such that profits generated from these sites are equal. We show further that the optimal pricing increases logarithmically with the density of EV charging sites.

The optimal decision on choosing which EVCS sites to build (or deferring investment) is more complicated and is combinatorial in nature. We provide a greedy heuristic and show that the heuristic is asymptotically optimal as the density of EVCS sites increases.

Under the assumption of the uniform vehicle preference, similar results are also obtained. The optimal purchasing decision of a consumer is again a threshold policy on the vehicle preference. There is, however, a dead zone effect of the EVCS density. Specifically, when the density of EVCSs is lower than some threshold, the EV market share is zero.

\subsection{Related works and organization}

There is an extensive literature on two-sided markets and indirect network effects for various products; see e.g., the compact disc (CD) player and CD title markets (Gandal et al., 2000), the video game console and video game markets (Clements and Ohashi, 2005; Corts and Lederman, 2009; Zhou, 2014), the hardware and software markets (Dubé et al., 2010), the credit card market (Armstrong and Wright, 2007), and the yellow page and advertisement markets (Rysman, 2004). Previous work on indirect network effects dates back to early theoretical studies such as (Rohlfs, 1974; Katz and Shapiro, 1985; Farrell and Saloner, 2003). Rochet and Tirole (2004) firstly proposed a restrictive definition to distinguish between one-sided and two-sided markets in the context of charge per usage. Caillaud and Jullien (2003) pointed out that, one side of the market always waits for the action from the other side. It is thus critical for players to take the right move during the initial stages of the product diffusion.

Exploratory researches on the diffusion of vehicles with alternative fuels have been conducted. Surveys were carried out to study the consumer attributes on conventional vehicles and plug-in EVs in (Kurani et al., 1996; Potoglou and Kanaroglou, 2007; Lebeau et al., 2012; Delang and Cheng, 2012). The role of consumer environmental awareness and signaling in the market for traditional hybrid vehicles is examined in Kahn, 2007; Kahn and Vaughn, 2009) and (Sexton and Sexton, 2014). The impacts of government programs both at the federal and 
state level in promoting the adoption of hybrid vehicles are examined in recent studies, including (Beresteanu and Li, 2011; Gallagher and Muehlegger, 2011) and (Sallee, 2011). On the other hand, Bunch et al. (1993) established and estimated a nested multinomial logit model for the clean-fuel vehicles demand. Similar discrete decision model of vehicle is used in (Ewing and Sarigöllü,, 1998; Gao and Kitirattragarn, 2008; He et al., 2012; Hackbarth and Madlener,

2013) to study the preference of hybrid electric vehicle. It is pointed out that charging convenience is a major concern when consumers make the purchase but no analytical result of impact of EV market performance on EVCS investment is presented.

There is a growing literature on the EVCS investment from the operation research and engineering perspectives. For example, the charging station deployment has been formulated as an optimization problem from the social planner's point of view in (Shao-yun et al., 2012; Frade et al., 2011; He et al., 2013; Chen et al., 2013b). A location competition problem of charging stations is considered in (Bernardo et al., 2013), where a discrete decision model of charging stations similar to this paper is used. Efficient design of large scale charging is presented in (Chen and Tong, 2012) and the competition of charging operations is considered in (Chen et al., 2013a).

There is a rich literature on externalities in the new technology market (Jaffe and Stavins, 1994; Economides, 1996; Arthur, 1989; Bresnahan and Greenstein, 1999; Mever and Winebrake, 2009). Jaffe and Stavins (1994) examine the energy efficient technologies in buildings and suggest that energy paradox could be driven by a host of factors such as the information problem and unobserved costs of new technologies. Economides (1996) points out that the network externality is often observed in non-network industries that the value of a unit of good increases with the number of units sold. Arthur (1989) examines the outcomes of two competing new technologies under various conditions and shows that the new technology market gradually lock itself into an outcome that is not entirely predictable in advance. Bresnahan and Greenstein (1999) characterize the equilibrium and strategic behavior within each segment of the computer industry and explain the dramatic change of the market in 1990s. More closely related to our work is Meyer and Winebrake (2009) which is the first articles to explore the indirect network effects between alternative fuel vehicles and refueling stations. The multinomial logit model of vehicle choice considered in Meyer and Winebrake (2009) is similar to the consumer vehicle choice model in this paper. However, Meyer and Winebrake (2009) consider only the consumer vehicle choice without modeling the investment decision on refueling stations and provide simulation results under various scenarios. Our paper focuses on the EV market and provides a theoretical analysis that simultaneously models the two-sides of the market: consumer adoption of EVs and investment decision of charging stations.

The work of Li et al. (2014) and the current paper represent the first analysis of the twosided EV and EVCS market and the related indirect network effects. The work in (Li et al., 2014) focuses on an empirical study of indirect network effects whereas the current paper focuses on the theoretical analysis. In particular, this paper extends the model in (Yu et al., 2014) by allowing (unobserved) vehicle preferences to have a type I extreme value distribution consistent with the discrete choice model (McFadden, 1974). Also new in this paper are the comparison between the market solution and the decisions of the social planner and the effects of subsidies for EV purchase and EVCS investments.

This paper is organized as follows. The structure of the two-sided market and a sequential game model are described in Section 2 The solution to the game is obtained by backward induction. In Section 3 the consumers' model and the optimal decisions are obtained. The investor's model and optimal strategy are presented in Section 4, as well as the social welfare 
optimization. Discussions about different effects of subsidies and the difference between the private market solution and the socially optimal solution are presented in Section 5. Section 6 concludes the paper.

\section{A Sequential Game Model}

In this section, we formulate the two-sided market as a two-player sequential game model with perfect and complete information. We introduce the basic structure of the EV-EVCS market, define the players of the game, and specify the decision process.

\subsection{Two-sided market structure}

A two-sided market typically has a structure as illustrated in Fig. 2, where we use a generic hardware-software market as an example to describe its basic components. A two-sided market includes a set of platforms, say, Macbook ${ }^{\mathrm{TM}}$ and the OS X operating system as a hardwaresoftware platform by Apple Inc. vs. Dell's Inspiron ${ }^{\mathrm{TM}}$ and the Windows 8 as an alternative.

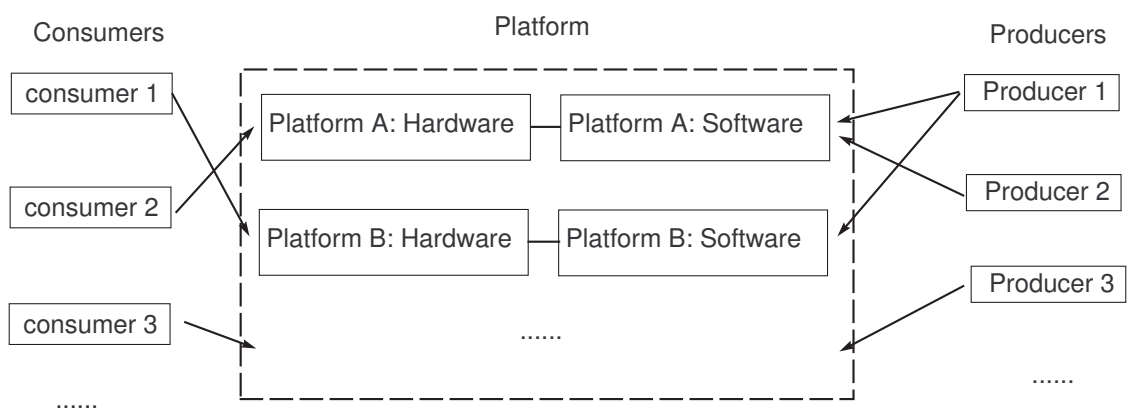

Figure 2: The structure of a two-sided market.

On the one side of the platforms is the consumer who makes her purchase decisions based on her platform preferences, the costs of the platforms, and the available softwares for different platforms. On the other side of the platforms are the software developers who invest in developing softwares for one particular platform or multiple platforms. The software developer makes his decision based on, among other factors, the costs of developing softwares and the popularity of platforms.

In Fig. 3, we present the two-sided EV market in this paper. There are two platforms: one is the EV as the "hardware" and the EVCS as the "software". The other is the conventional gasoline vehicle as the "hardware" and the gas station as the "software". On the one side of the platforms are the consumers who decide which type of vehicles to purchase based on the cost of EVs, the available charging stations, and the cost of charging. On the other side of the platforms is an investor who decides to build and operate charging stations or to defer his investment and earn interest at a fixed rate 2 .

\footnotetext{
${ }^{2}$ Because we focus on the early stage of EV diffusion in an environment that gas stations are already well established, the alternative of EVCS investor is not building additional gas stations.
} 


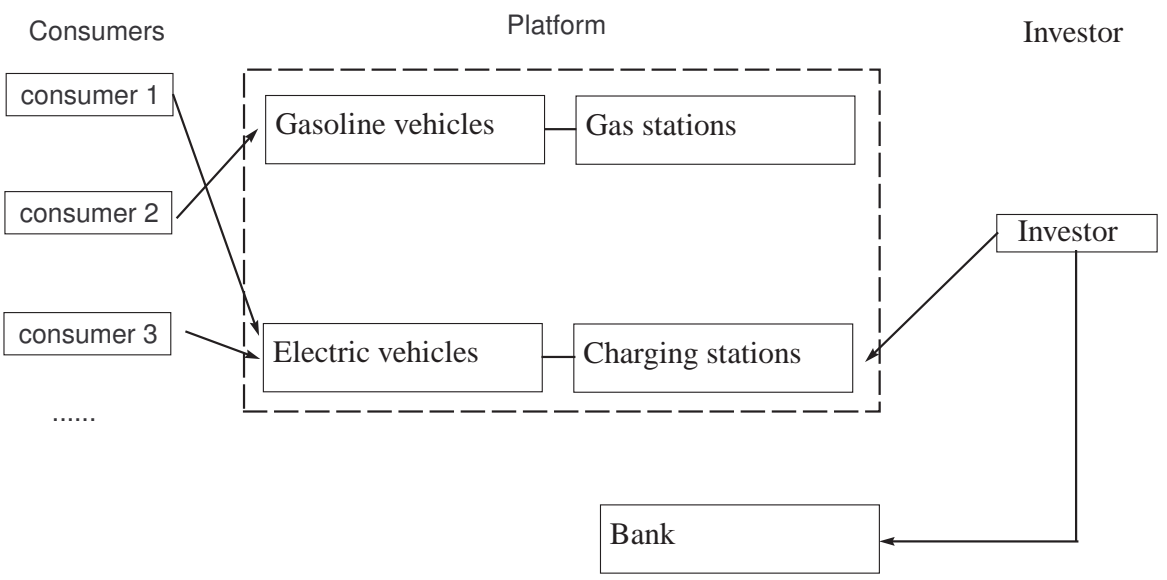

Figure 3: The two-sided market model of EVs and EVCSs.

\subsection{The investor's decision model}

We assume that the investor is both the builder and the operator of EVCSs. The monopoly assumption is valid at the launch stage of EVCS market since the investment is mainly conducted by the EV manufactories or the government. The investor's decision has two components: the first is an investment decision on whether to build EVCSs from a list of candidate sites or to defer his investment. The second is an operation decision on pricing the charging services at those built locations. The type of the charging station to be built is another decision component since the building cost of the charging stations are dramatically different and the cost of charging time is an important concern of consumers when choosing charging service. In this work, we assume the charging rate of the EVCSs is the level 2 charging, the dominant charging rate for the public charging stations on the market. The major concern of the DC fast charging is the potential damage to the battery and its impact on the grid.

Let $\mathscr{C}=\left\{s_{i}=\left(f_{i}, c_{i}\right), i=1, \cdots, N_{L}\right\}$ be the set of candidate sites for charging stations known to the investor. Site $s_{i}=\left(f_{i}, c_{i}\right)$ has two attributes: the favorability rating $f_{i}$ and the marginal operating $\cos \sqrt{3} c_{i}$. The favorability rating $f_{i}$ represents the characteristics of charging stations. It may include but not limited to variations in accessibility and availability of ancillary services. Accessibility refers to how easy it is for consumers to access the charging station and potentially affects the volume of the passenger flow. A similar discussion is presented for gas stations by Salop and Hotelling (1979; 1990). For example, a site at workplace parking lots may be more attractive than a location that is less frequently visited by consumers. Ancillary services refers to other services that a charging station may provide such as vehicle repair and super markets. Kroger, the largest grocery store owner of the U.S. has installed over 300 Level 2 and DC fast charging stations in key markets over the country (Green Retail Decisions, 2013). Walmart and Kohl's also expanded their charging stations (Green Retail Decisions, 2011, 2012). These public charging station locations are also favored by EV owners since they can charge while shopping.

\footnotetext{
${ }^{3}$ The marginal cost $(\$ /$ mile) here is marginal operating cost $(\$ / \mathrm{kWh})$ normalized by EV efficiency $(\mathrm{miles} / \mathrm{kWh})$.
} 
The operating cost $c_{i}$ may vary across stations because of different locational marginal price of wholesale electricity, the labor cost and other cost components.

Given $\mathscr{C}$ and the utility functions of the consumer, the investor's decision is denoted by $(C, \vec{\rho}) \in 2^{\mathscr{C}} \times \mathcal{R}^{|C|}$ where $C \subseteq \mathscr{C}$ is the set of locations selected to build charging stations and $\vec{\rho}=\left(\rho_{1}, \cdots, \rho_{|C|}\right) \in \mathcal{R}^{|\mathcal{C}|}$ the vector of charging prices at the built stations.

Assuming the consumer maximizes her utility, the investor chooses the investment sites and charging prices to maximize the investment profit within his budget $B$. The investment optimization is stated as

$$
\begin{array}{ll}
\max _{C, \vec{\rho}} & \Pi(C, \vec{\rho})-\sum_{i=1}^{|C|} F\left(s_{i}\right) \\
\text { subject to } & \sum_{i=1}^{|C|} F\left(s_{i}\right) \leq B
\end{array}
$$

where $\Pi$ is the operational profit and $F\left(s_{i}\right)$ the building cost of station $i$.

\subsection{The consumer's decision model}

The expected cost of owning and using an EV include the upfront capital cost and the expected future operating cost. The capital costs vary between EVs and gasoline cars reflecting different purchase costs of these two types of vehicles. Our model defines the expected future operating cost to be a function of expected gasoline price for gasoline cars and a function of expected electricity prices for EVs. The gasoline price can be thought of expected average gasoline price in the future. In case that gasoline prices follow a random walk as suggested by Anderson, Kellogg, Sallee Anderson et al. (2013), the benefit predictor of future gasoline prices would be current gasoline price.

A consumer observes the investor's decision on the location set of charging stations $C=\left\{s_{1}, \cdots, s_{N_{E}}\right\}$ and the charging price vector $\vec{\rho}=\left(\rho_{1}, \cdots, \rho_{N_{E}}\right)$ where $N_{E}$ is the number of charging stations. The consumer first chooses the type of vehicle to purchase. If the choice is an $\mathrm{EV}$, the consumer also decides on the location of charging. The action of the consumer is given by $\{v, k\}$ where $v \in\{E, G\}$ is the vehicle choice (either EVs or gasoline vehicles) and $k \in\left\{0,1, \cdots, N_{E}\right\}$ the preferred charging station. We include $k=0$ for the home charging option. The consumer chooses $\{v, k\}$ by maximizing the overall vehicle utility that includes the charging utility for the EV purchase.

For the vehicle choice, we assume a widely adopted discrete choice model with random utility functions (Bernardo et al., 2013). The consumer utility model of purchasing a vehicle is assumed as follows.

$$
\begin{aligned}
& V_{E}=\beta_{1} \mathbb{E}\left(U_{E}\right)-\beta_{2} p_{E}+\Phi+\epsilon_{E} \\
& V_{G}=\beta_{1} \mathbb{E}\left(U_{G}\right)-\beta_{2} p_{G}+\Phi+\epsilon_{G}
\end{aligned}
$$

where $U_{E}$ is the (random) charging utility of consumer's best choice defined in $\left[5, \mathbb{E}\left(U_{E}\right)\right.$ the expected maximum charging utility, $p_{E}$ the price of an EV, $\Phi$ the utility of owning a vehicle, and $\epsilon_{E}$ a random vehicle preference of $\mathrm{EV}$. Variables $\mathbb{E}\left(U_{G}\right), p_{G}$, and $\epsilon_{G}$ are similarly defined for the gasoline vehicle.

The coefficient $\beta_{1}$ captures the magnitude of the indirect network effects. More charging stations provide potentially higher charging utility of consumers, thus increases the utility of purchasing a electric vehicle. The charging utility $U_{E}$ captures the operation cost and charging time cost of EVs. The price of electricity is much lower than the price of gasoline which makes the operation cost of an EV much lower. However, the charging time cost of EVs offsets the benefit. In the charging utility model described in (4), we explicitly consider the effect of charging price. The charging time cost can be included by offsetting the favorability rating $f_{i}$ by a constant since we are considering only level 2 charging. The coefficient $\beta_{2}$ is the price elasticity of demand and captures consumer price sensitivity. The preference $\epsilon_{E}$ and $\epsilon_{G}$ represents the consumer 
preference of EVs and gasoline vehicles, including but not limited to quality and brand loyalty, driving experience, awareness of environment (Kahn, 2007; Kahn and Vaughn, 2009) and other demand shocks.

This consumer model is flexible and can be either short-term (EV leasing) or long-term (EV purchasing). In a framework of EV purchasing, the price $p_{E}$ would be the purchasing cost of electric vehicles. The charging utility is calculated during the life time of an EV. In a framework of EV leasing, the price $p_{E}$ would be the leasing cost of electric vehicles, for example, for three years, the duration of a typical leasing contract

The consumer's decision is then defined by

$$
\max \left\{V_{E}, V_{G}\right\}
$$

The optimization of consumer's vehicle decision also includes optimally choosing charging stations. Specifically, the consumer charging utility at station $i$ is assumed to be random in the following form.

$$
U_{i}=\alpha_{1} f_{i}-\alpha_{2} \rho_{i}+\epsilon_{i}, i=0, \ldots, N_{E}
$$

where $f_{i}$ is the favorability rating, $\rho_{i}$ the charging price determined by the investor, $\epsilon_{i}$ the random preference of charging station $i$. The coefficient $\alpha_{2}$ indicates the price sensitivity of the charging price of consumers.

Given the realization of the charging preference, $\vec{\epsilon}=\left(\epsilon_{0}, \ldots, \epsilon_{N_{E}}\right)$, the EV owner chooses charging station $k \in\left\{0,1, \ldots, N_{E}\right\}$ to maximize her charging utility, i.e.,

$$
U_{E}=\max _{k \in\left\{0, \ldots, N_{E}\right\}} U_{k}
$$

For the option of choosing a gasoline vehicle, the number/locations of gas stations will not change with the investor's decisions. Thus the expected maximum fueling utility, $\mathbb{E}\left(U_{G}\right)$, is a constant.

The indirect network effect between the EV market and the EV charging station market is reflected by the investment decision of the investor and the charging utility $U_{E}$. A shock to the system, for example a tax credit, would stimulate the sale of EVs, which will bring more profit to the charging stations and attract the investor to build more charging services. In the other hand, more charging stations make the charging more convenient and result in a greater charging utility $U_{E}$. When $\beta_{1}$ is statistically significant, more consumers will choose to purchase an EV. The impact would circle back and forth between the decisions of consumers and the investor and form a positive feedback loop in both sides of the market (Li et al., 2014).

\subsection{The sequential game model}

The sequential game structure of the two-sided EV-EVCS market is summarized as follows.

- The investor's decision is defined by the optimization in (1). Specifically, given the set of locations, $\mathscr{C}$, the investor decides to invest (build and operate) charging stations at a subset $C \subseteq \mathscr{C}$ and determines the charging price $\vec{\rho}$. When $C=\emptyset$, the investor defers his investment and earns interest at a fixed rate.

- The consumer's decision is defined by (3-5]. Specifically, having observed the investor's decision, $\{C, \vec{\rho}\}$, the consumer chooses $v \in\{E, G\}$. If $v=E$, the consumer also chooses charging stations to charge by maximizing her charging utility. 
The dynamic game is solved by backward induction. In particular, we first consider the consumer's decision by fixing the investor's choice of charging locations and charging prices. The optimal consumer's decision is given in Section 3 . In Section 4 the optimal investor's decision is presented.

\section{Consumer Decisions}

\subsection{Consumer Decision Model and Assumptions}

We first summarize the assumptions of the consumer model given in Section 2.3

A1. Consumers are identical and their decisions are statistically independent. Without loss of generality, we focus on the decision of a single consumer.

A2. The average charging demand is normalized to 1 .

A3. The random preference of charging station $i, \epsilon_{i}$, is independent and identically distributed (IID) and follows the type I extreme value distribution with the probability density function (PDF)

$$
f(\epsilon)=e^{-\epsilon} e^{-e^{-\epsilon}} .
$$

A4. The random preference of vehicles $\epsilon_{E}$ and $\epsilon_{G}$ are statistically independent.

The type I extreme value distribution is widely used in the discrete choice model. McFadden firstly introduced it in the consumer choice theory and showed it leads to the multinomial logit distribution across choices (McFadden, 1974).

\subsection{Consumer Decisions and EV Market Share}

The main result in this section is the structure of the optimal vehicle decision and the characterization of the EV market share as shown in the following theorem.

Theorem 1 (Consumer choice and EV market share). 1. If the vehicle preferences $\epsilon_{E}$ and $\epsilon_{G}$ follow the type I extreme value distribution, the optimal consumer decision is a threshold policy on the difference of the vehicle preferences $\epsilon_{E}-\epsilon_{G}$ :

$$
\begin{cases}\epsilon_{E}-\epsilon_{G} \geq \tau_{e} & \text { purchase electric vehicles } \\ \epsilon_{E}-\epsilon_{G}<\tau_{e} & \text { purchase gasoline vehicles }\end{cases}
$$

where

$$
\tau_{e}=\beta_{1} \mathbb{E}\left(U_{G}\right)-\beta_{2} p_{G}-\beta_{1} \ln \left[\sum_{i=0}^{N_{E}} \exp \left(\alpha_{1} f_{i}-\alpha_{2} \rho_{i}\right)\right]+\beta_{2} p_{E} .
$$

The EV market share is given by

$$
\eta_{e}=\frac{q^{\beta_{1}}}{q^{\beta_{1}}+C},
$$

where $C=\exp \left[\beta_{1} \mathbb{E}\left(U_{G}\right)-\beta_{2} p_{G}+\beta_{2} p_{E}\right]$ and $q=\sum_{i=0}^{N_{E}} \exp \left(\alpha_{1} f_{i}-\alpha_{2} \rho_{i}\right)$. 
2. If the vehicle preference of $E V$ is uniformly distributed with $\epsilon_{E} \sim \mathcal{U}(0,1)$ and $\epsilon_{G}=1-\epsilon_{E}$, the optimal consumer decision is a threshold policy on the realization of the consumer preference $\epsilon_{E}$,

$$
\begin{cases}\epsilon_{E} \geq \tau_{u} & \text { purchase electric vehicles } \\ \epsilon_{E}<\tau_{u} & \text { purchase gasoline vehicles }\end{cases}
$$

where

$$
\tau_{u}=\left[\left[\beta_{1} \mathbb{E}\left(U_{G}\right)-\beta_{2} p_{G}-\beta_{1} \ln (q)+\beta_{2} p_{E}+1\right] / 2\right]_{0}^{1} .
$$

The EV market share is given by

$$
\eta_{u}=1-\tau_{u}
$$

3. Under both assumptions, the charging service market share captured by charging station $i$ is given by

$$
P_{i}=\frac{\exp \left(\alpha_{1} f_{i}-\alpha_{2} \rho_{i}\right)}{\sum_{k=0}^{N_{E}} \exp \left(\alpha_{1} f_{k}-\alpha_{2} \rho_{k}\right)} \triangleq \frac{q_{i}}{q} .
$$

Proof. To derive the optimal consumer vehicle decision from (2) 3], we first compute the expected maximum charging utility from (5) using the type I extreme value distribution of $\epsilon_{i}$. Specifically,

$$
\begin{aligned}
\mathbb{E}\left(U_{E}\right) & =\ln \left[\sum_{k=0}^{N_{E}} \exp \left(\alpha_{1} f_{k}-\alpha_{2} \rho_{k}\right)\right] \\
& \triangleq \ln \left(\sum_{k=0}^{\bar{N}_{E}} q_{k}\right)=\ln (q),
\end{aligned}
$$

where $q_{k}=\exp \left(\alpha_{1} f_{k}-\alpha_{2} \rho_{k}\right)$.

Next, by substituting $\mathbb{E}\left(U_{E}\right)$ into $(2)$, the consumer's optimal vehicle choice is given by a threshold policy on $\epsilon_{E}-\epsilon_{G}$. In particular, the consumer purchases an $\mathrm{EV}$ if

$$
\epsilon_{E}-\epsilon_{G} \geq \beta_{1} \mathbb{E}\left(U_{G}\right)-\beta_{2} p_{G}-\beta_{1} \ln (q)+\beta_{2} p_{E} .
$$

Under the assumption of uniform distribution, by substituting $\epsilon_{G}=1-\epsilon_{E}$ into (12), we have (8).

From (McFadden, 1974, chap. 4), the EV market share and the EVCS market share are given by (7), (9) and (10).

From the expression of the market share, we can explore the effects of operational cost and capital cost of EVs and gasoline vehicles. When the price elasticity $\beta_{2}$ is positive, the EV market share is inversely proportional to the exponential price difference between EVs and gasoline vehicles in the extreme preference case. In the uniform preference case, the market share is linear in the price difference with a negative slope $\left(-\beta_{2} / 2\right)$. The effect of charging is reflected in the sum of exponential utilities $q$. Lower charging cost will increase $q$ thus benefit the EV market share. Meanwhile, limited number of charging station will bring down the exponential utilities and hinder the successful launch of EVs. The threshold on the consumer vehicle preference is a linear combination of the difference in the capital cost and the operational utility (charging utility) between the EVs and gasoline vehicles.

With Theorem 1 , we examine the trend of EV market share as a function of the charging station density, the charging price, and the price of EV. In particular, under both preference assumptions, the expressions of EV market share is an increasing and concave function of the number of available charging stations. This means that the marginal return of building additional charging stations reduces with the number of available charging stations. 
Fig. 4(a) and 4(b) show numerical evaluations of the market share as the density of charging stations. In addition to the concavity of the market share function, we also observe that the market share accelerates faster with a lower EV purchasing price.

For the uniform preference model, Fig. 4(a) shows a dead zone effect, as a result of the ceiling operation in (8). In particular, the EV market share is zero unless the density of charging stations exceeds a certain level. In addition, we see that lowering EV purchasing cost helps the market share escaping the dead zone. Fig. 5(a) shows that the critical density of charging stations at which the market share becomes positive grows as a "convex" function of the EV purchasing price. The convexity of this function means that the requirement of initial investment on EVCSs stiffens as the cost of EV purchase increases.

Under the extreme value distribution assumption, there is no dead zone effect. The EV market share $\eta_{e}$ is always positive. However, if we treat $\eta_{e} \leq 5 \%$ as a launch failure of EV, there is a critical density below which EV is considered failed. In Fig. 5(b), the critical density of EVCSs is shown to have a "convex" shape in terms of EV prices.

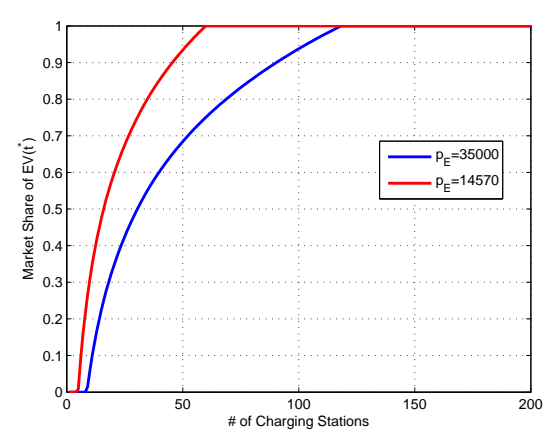

(a) Uniform preference distribution.

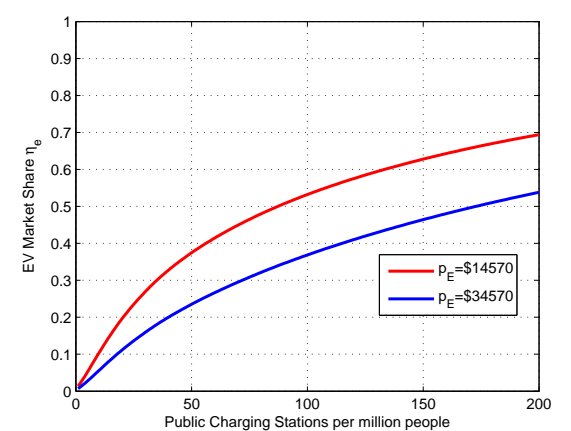

(b) Type I extreme value preference distribution.

Figure 4: EV market share vs. density of charging stations. $p_{G}=\$ 17450$, $\mathbb{E}\left(U_{G}\right)=4.5052, \rho_{i}=0.2 \$ / \mathrm{kWh}$.

The "convex" shape of the critical density of EVCSs in terms of EV prices implies at least two points regarding the successful launch of EVs. From the manufacturers' point of view, the higher the MSRP is, the harder the EV would survive not only due to the prohibitive price but also the gap between the existing number and desired number of EVCSs. Thus lower price would not only attract consumers to purchase EVs but also alleviate the strain of building more charging stations. From the government point of view, it is important to determine the subsidy policy considering that what range the price of EVs lies in. When the price of EV is extremely high, giving more subsidy to EV purchasing would significantly reduce the required number of EVCSs. But as the subsidy increases, the effect on reducing the required number of EVCSs is getting smaller. At some point, it will be less effective to subsidize the EV purchasing than to build more charging stations. This phenomenon is also confirmed in the empirical simulation in Li et al., 2014) that building charging stations may be a more effective way to boost EV sales in the EV launch stage. 


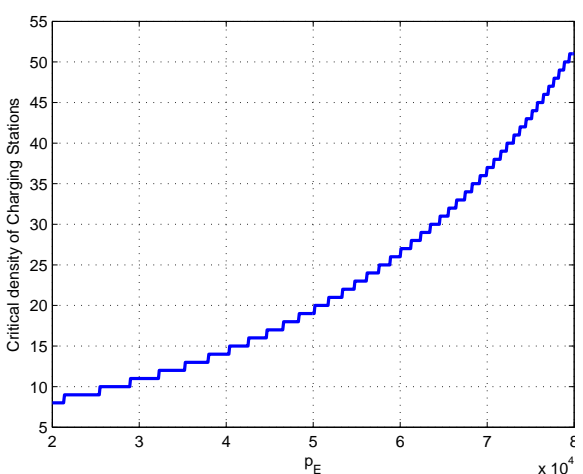

(a) Uniform preference distribution

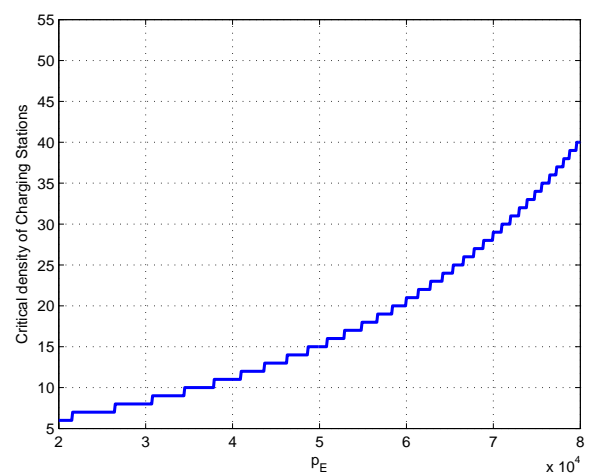

(b) Type I extreme value preference distribution

Figure 5: Critical density of charging stations vs. EV price $p_{E} \cdot p_{G}=\$ 17450$, $\mathbb{E}\left(U_{G}\right)=4.5052, \rho_{i}=0.2 \$ / \mathrm{kWh}$.

\section{Investor Decisions}

After the discussion about the consumer model and her decision, we now focus on the investor decision model that includes the selection of the charging stations locations and the optimal pricing of charging.

\subsection{Investor Decision Model and Assumptions}

We make the following assumptions about the investor model:

B1. We consider a single investor who also operates all charging stations. This implies the monopolistic competition in the charging service market.

B2. We assume that the deferred investment earns interest at a rate of $\gamma$.

B3. The investor knows the utility functions of the consumers.

To solve the optimization in (1), we proceed with backward induction. In Section 4.2, we find the optimal pricing with fixed EVCS locations. In Section 4.3 we optimally choose the charging station locations.

\subsection{Optimal Charging Price}

Given the set of charging station locations $C$, the investor determines the optimal charging price $\vec{\rho}$ to maximize the life time discounted total operation profit. Specifically, the investor has the following optimization.

$$
\max _{\vec{\rho}} \Pi=\max _{\vec{\rho}} N_{c} D \eta(\vec{\rho}) \sum_{i=1}^{N_{E}} P_{i}(\vec{\rho})\left(\rho_{i}-c_{i}\right),
$$

where $N_{c}$ is the total amount of consumers (householders), $D$ the discounted life time driving mileage of a typical EV, $\eta(\vec{\rho})$ the expected EV market share given in Theorem 1 (here we make 
the dependency on charging price explicit), $P_{i}(\vec{\rho})$ the market share of station $i$, i.e., the fraction of EV owners who charge at station $i$, and $c_{i}$ the marginal operation cost of station $i$. The optimal charging price $\rho_{i}^{*}$ is given by the following theorem.

Theorem 2 (Charging price). For fixed set of charging stations $C=\left\{\left(f_{i}, c_{i}\right), i=1, \cdots, N_{E}\right\}$, the optimal charging price $\rho_{i}^{*}, i=1, \cdots, N_{E}$ generates uniform profits across charging stations. In particular,

1. Under the type I extreme value vehicle preference distribution assumption,

$$
\rho_{i, e}^{*}-c_{i}=\frac{1}{\alpha_{2} \beta_{1}\left(1-\eta_{e}\left(\vec{\rho}_{e}^{*}\right)\right)\left(1-P_{0}\left(\vec{\rho}_{e}^{*}\right)\right)+\alpha_{2} P_{0}\left(\vec{\rho}_{e}^{*}\right)},
$$

where $\eta_{e}$ is the market share of $E V, \vec{\rho}_{e}^{*}=\left(\rho_{1, e}^{*}, \ldots, \rho_{N_{E}, e}^{*}\right)$ the vector of optimal charging price, $\rho_{0, e}$ the cost of charging at home, and $P_{0}\left(\vec{\rho}_{e}^{*}\right)=\frac{\exp \left(\alpha_{1} f_{0}-\alpha_{2} \rho_{0, e}\right)}{\exp \left(\alpha_{1} f_{0}-\alpha_{2} \rho_{0, e}\right)+\sum_{k=1}^{N_{E}} \exp \left(\alpha_{1} f_{k}-\alpha_{2} \rho_{k, e}^{*}\right)}$ the probability that the consumer charges at home.

2. Under the uniform vehicle preference distribution assumption,

$$
\rho_{i, u}^{*}-c_{i}=\frac{1}{\frac{\alpha_{2} \beta_{1}\left(1-P_{0}\left(\vec{\rho}_{u}^{*}\right)\right)}{2 \eta_{u}\left(\vec{\rho}_{u}^{*}\right)}+\alpha_{2} P_{0}\left(\vec{\rho}_{u}^{*}\right)},
$$

where $\eta_{u}, \vec{\rho}_{u}^{*}, \rho_{0, u}$, and $P_{0}\left(\vec{\rho}_{u}^{*}\right)$ are similarly defined.

Proof. This is a direct consequence of the first order optimality condition.

Note that the right hand sides of equation (14) and (15) are the same for any charging station $i \in\left\{1, \ldots, N_{E}\right\}$. This means that the profits generated from different charging stations are the same. Equation (14) and (15) do not have closed-form solutions but the optimal prices can be solved numerically. Since $0<P_{0}\left(\vec{\rho}_{j}^{*}\right)<1$ and $0<\eta_{j} \leq 1$ for either $j \in\{e, u\}$, the revenue is strictly positive. The indirect network effect from the EV market can be found in both charging profit and the total profit. In both uniform and extreme preference cases, if there is a shock in the EV market share, the uniform profit across charging stations will increase and the total profit will also grow, which will encourage the investment in more charging stations.

The profit across different charging stations is the same. However, since the operating cost across charging stations is different, the charging price of stations varies. Intuitively, more attractive charging stations have higher operating cost (labor cost, electricity price, and so on), thus higher charging price. Consumers balance the convenience of the station and the charging cost and make charging decisions. The price of gasoline and gasoline vehicles affects the charging profit indirectly through the EV market share $\eta$. The lower the gasoline price and gasoline vehicle price are, the smaller the EV market share is and this brings down the charging profit of charging stations.

As $N_{E} \rightarrow \infty$, the public charging of EV becomes more and more convenient, which not only motivates consumers to purchase EVs but also encourages them to charge outside home. As a result, the EV market share $\eta_{j} \rightarrow 1$ and the fraction of charging at home $P_{0}\left(\vec{\rho}_{j}^{*}\right) \rightarrow 0$. Based on this trend, we have the convergence of the marginal charging profit shown in the following theorem.

Theorem 3 (Charging price convergence). Consider a fixed set of charging stations $C=\left\{\left(f_{i}, c_{i}\right), i=1, \cdots, N_{E}\right\}$. Let $v=\sum_{i=1}^{N_{E}} \exp \left(\alpha_{1} f_{i}-\alpha_{2} c_{i}\right)$ be the sum of exponentials of systematic charging utilities. 
1. For the extreme distributed vehicle preference, the per-charging station profit $r_{e}=\rho_{i, e}^{*}-c_{i}$ grows logarithmically with the sum utilities, i.e.,

$$
r_{e}=\ln v / \alpha_{2}+o(\ln v) .
$$

2. For uniformly distributed vehicle preference, the charging profit $r_{u}=\rho_{i, u}^{*}-c_{i}$ is strictly increasing with the number of charging facilities and converges to a constant. Specifically,

$$
r_{u}=2 / \alpha_{2} \beta_{1}+o(1)(v \rightarrow+\infty) .
$$

Proof. See Appendix A.1.

In Theorem 3 the increasing per-charging station profit is because of the assumption of monopolistic investor. More charging stations motivate more consumers to purchase EVs and bring larger charging demand. The investor will take the advantage and set a higher markup. In both cases, the profit increase corresponding to the increase of number of charging stations $N_{E}$ (or equivalently, $v$,) is decreasing, which is due to the diminishing of the network effect.

The profit is also affected by the consumer sensitivity to the charging price. When consumers are more sensitive to the price ( $\alpha_{2}$ is large), the optimal charging price is close to the marginal cost across charging stations.

The different convergence comes from different preference assumptions. Under the extremely distributed preference assumption, the EV market share strictly increases as the density of EVCSs increases. Thus the profit grows logarithmically because of the expanding charging demand. While under the uniform distributed preference assumption, the EV market share reaches the upper limit when there are enough EVCSs. So the profit converges to a constant.

\subsection{Optimal Charging Station Locations}

After the discussion about the optimal charging price, we consider the choice of charging station locations. Given the set of location candidates $\mathscr{C}=\left\{s_{i}=\left(f_{i}, c_{i}\right), i=1, \cdots, N_{L}\right\}$, the investor has the following optimization.

$$
\begin{array}{ll}
\max _{C \subseteq \mathscr{C}} & \Pi\left(C, \vec{\rho}_{j}^{*}(C)\right)-\sum_{i=1}^{|\mathcal{C}|} F\left(s_{i}\right) \\
\text { subject to } & \sum_{i=1}^{\mid \mathcal{C}} F\left(s_{i}\right) \leq B
\end{array}
$$

where $F\left(s_{i}\right)$ is the building cost of charging station $s_{i}$ and $\Pi\left(C, \vec{\rho}_{j}^{*}(C)\right)$ the operational profit.

In general, the optimal investment decision from (18) requires combinatorial search for $C$, which is computationally inefficient and sometimes not tractable. However, the convergence of the optimal charging prices across charging stations in Theorem 3 makes it possible to separate the price decision and the location choice, which leads to a linear complexity heuristic algorithm.

The Greedy Investment Algorithm (GIA) given in Algorithm 1 first ranks the charging stations by the exponential systematic part of the charging utility, $v_{i}=\exp \left(\alpha_{1} f_{i}-\alpha_{2} c_{i}\right)$. It then adds charging stations to the investment list one at a time in the decreasing order of exponential systematic utility $v_{i}$ until either the budget is exhausted or the cumulated profit starts to decrease.

By ignoring the dependency of charging locations in the marginal charging profit $\left(\rho_{i, j}^{*}-c_{i}\right)$ in (18), the GIA is not optimal in general. As $N_{E}$ increases, however, the marginal charging profit increases and converges, which makes the algorithm asymptotically optimal. 


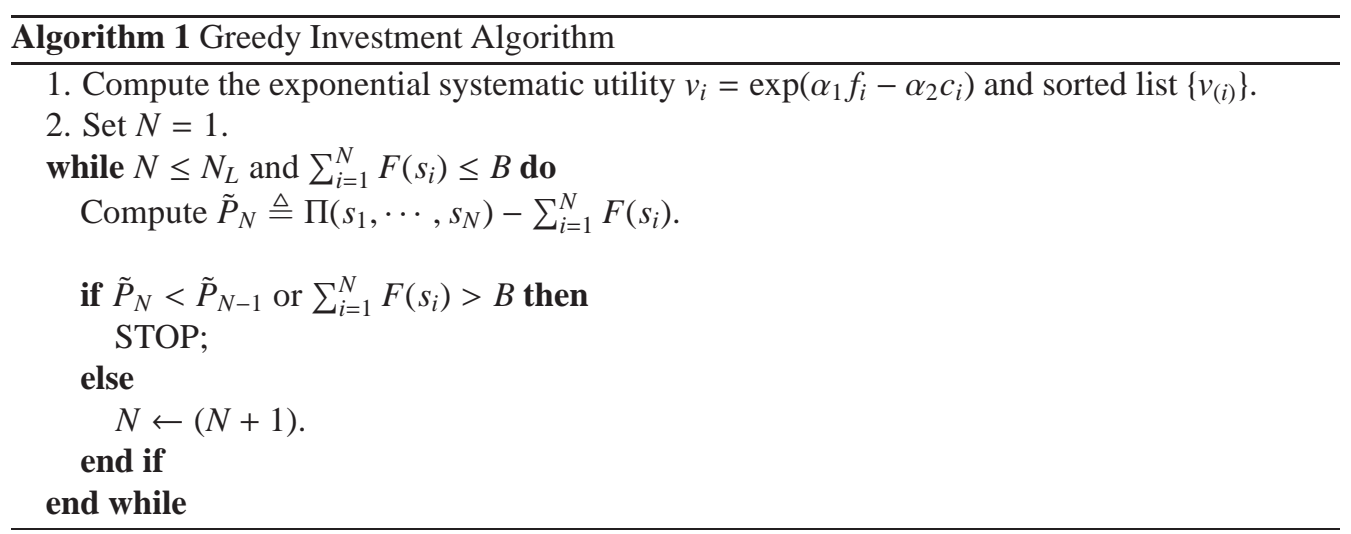

Theorem 4 (Asymptotic optimality). Assume the building costs of charging stations are constant, i.e., $F\left(s_{i}\right)=(1+\gamma) F_{0}$, where $\gamma$ is the interest rate. There exists an $M>0$ such that when $N>M$, the greedy algorithm is optimal under both the type I extreme value distribution and the uniform distribution assumption.

Proof. See Appendix A.2.

After obtaining the optimal set of charging stations $C^{*}$ and the optimal charging price vector $\vec{\rho}_{j}^{*}$, the investor makes the investment if the investment profit $\left[\Pi\left(C^{*}, \vec{\rho}_{j}^{*}\right)-\sum_{i=1}^{\left|C^{*}\right|} F\left(s_{i}\right)\right]$ is positive. Otherwise, the investor will defer his investment and earn interest at rate $\gamma$.

To make $\left[\Pi\left(C^{*}, \vec{\rho}_{j}^{*}\right)-\sum_{i=1}^{\left|C^{*}\right|} F\left(s_{i}\right)\right]$ positive, the EV price and the building costs of charging stations need to be low enough, which implies that the subsidies for EV purchase and charging stations are necessary to the successful launch of EV. Meanwhile the price of gasoline and electricity affect the charging profit $\Pi$. The high petroleum price and cheap electricity benefit the EV market.

\subsection{Social welfare optimization}

We now consider the investment problem from the viewpoint of a social planner who makes investment decisions based on social welfare maximization and compare the difference between the solution of the private market defined in Section 4.3 and that of a social planner.

Recall the investor utility $S_{I}\left(C, \vec{\rho}_{j}\right)$ and the consumer utility $S_{C}\left(C, \vec{\rho}_{j}\right)$ given in (1) and (3):

$$
\begin{aligned}
& S_{I}\left(C, \vec{\rho}_{j}\right)=\Pi\left(C, \vec{\rho}_{j}\right)-\sum_{i=1}^{|C|} F\left(s_{i}\right), \\
& S_{C}\left(C, \vec{\rho}_{j}\right)=\mathbb{E}\left[\max \left\{V_{E}\left(C, \vec{\rho}_{j}, \epsilon_{E}\right), V_{G}\left(\epsilon_{G}\right)\right\}\right] .
\end{aligned}
$$

Under the type I extreme value vehicle preference distribution assumption, the consumer utility is stated as

$$
\begin{aligned}
& S_{C}\left(C, \vec{\rho}_{e}\right)=\ln \left[\left(\sum_{i=0}^{|C|} \exp \left(\alpha_{1} f_{i}-\alpha_{2} \rho_{i, e}\right)\right)^{\beta_{1}} C_{1}+C_{2}\right], \\
& C_{1}=\exp \left(-\beta_{2} p_{E}+\Phi\right), C_{2}=\exp \left[\beta_{1} \mathbb{E}\left(U_{G}\right)-\beta_{2} p_{G}+\Phi\right] .
\end{aligned}
$$

Under the uniform vehicle preference distribution assumption, the consumer utility is stated as:

$$
S_{C}\left(C, \vec{\rho}_{u}\right)=\left[\left(\eta_{u}\left(C, \vec{\rho}_{u}\right)\right)^{2}+\beta_{1} \mathbb{E}\left(U_{G}\right)-\beta_{2} p_{G}+\Phi-\frac{1}{2}\right] \text {. }
$$


Assume that the social planner does not operate the charging station thus can not determine the charging price or the vehicle price. He only determines the set of charging stations locations to build by regulation. For example, Beijing government recently requires $18 \%$ of parking lots in new residential communities have to install charging stations (Loveday, 2014).

The social planner's decision is stated as:

$$
\begin{array}{ll}
\max _{C \subseteq \mathscr{C}} & \lambda N_{c} S_{C}\left(C, \vec{\rho}_{j}^{*}(C)\right)+S_{I}\left(C, \vec{\rho}_{j}^{*}(C)\right) \\
\text { subject to } & \sum_{i=1}^{|C|} F\left(s_{i}\right) \leq B
\end{array},
$$

where $N_{c}$ is the total amount of consumers (householders), $\vec{\rho}_{j}^{*}(C)$ the vector of the optimal charging prices determined by the charging station operators given the charging station locations, and $\lambda>0$ the weight of the consumers surplus.

The greedy investment algorithm in Table 1 can also be applied to solve for the social welfare optimized investment in charging stations. The following theorem characterizes the difference between the social welfare optimal solution and the market solution.

Theorem 5 (Social welfare). Let $C^{*}$ be the optimal set of charging stations determined by the investor, and assume $\left|C^{*}\right| \gg 1$. Let $C^{* *}$ be the optimal charging locations determined by the social planner. Under both the type I extreme value distribution and the uniform distribution assumptions, $\left|C^{* *}\right|>\left|C^{*}\right|$.

Proof. See Appendix A.3.

Theorem 5 implies that the monopolistic market solution tends to under-build charging stations. The under-provision of EVCSs and lower adoption of EVs relative to the socially optimal outcomes are due to two types of market failures: market power and indirect network effects (or externalities). The assumption of monopolistic investor leads to under-provision of EVCSs and a higher charging price than a competitive solution. This will in turn lead to a lower EV adoption. Therefore, introducing competition in EVCS provision will help EV diffusion. While this form of market failure is a result of our model setup and can be relaxed, the second form of market failure is inherent in the EV market as empirically confirmed in ( $\mathrm{Li}$ et al., 2014). Indirect network effects are externalities which are not accounted for in individual investment and purchase decisions. They will lead to a wedge in socially optimal outcomes and market outcomes, which justifies government interventions. For example, government can provide subsidies to charging station investors as the U.S. DOE does through various funding programs or mandate the provision of charging stations in real estate development as recently implemented in China (Loveday, 2014).

\section{Discussions}

\subsection{Effects of subsidy}

We consider here the effects of subsidy, either to EV consumers or to the investor of EV charging stations. The results obtained in Section 3 and Section 4 provide the basis for numerical results presented here.

Fixing the total policy budget as 230 million dollars, we vary the weight of subsidy for EV purchase among the total policy budget. A bisection algorithm is applied to search for the subsidy amounts for each EV and EVCS so that the constraints of total budget and budget weight are satisfied. 
Fig. 6(a) shows the EV market share against subsidy weight with different values of $\beta_{2}$. In the utility model (2), $\beta_{2}$ represents the consumer sensitivity to the EV price. When $\beta_{2}$ was large, consumers cared more about the EV price than the characteristics of charging facilities. Increasing EV subsidy dramatically boostd up the EV market share. On the other hand, when $\beta_{2}$ was close to 0 , consumers mainly concerned about the charging services and the subsidy for EV purchase played a tiny role in the EV market share evolution.

Similar impact exists in the EVCS market. As shown in Fig. 6(b) when $\beta_{2}$ was large, the consumer was more sensitive to EV price. In this case, the policy of subsidizing the EV purchase was more effective, not only in stimulating the $\mathrm{EV}$ purchasing but also driving the investor to deploy more charging facilities because of the EV popularity. When $\beta_{2}$ was close to 0 , consumers were less price sensitive. In this case, putting more weight to EV subsidy was less helpful. While subsidizing the charging station encouraged the investment in charging services which also benefited the EV consumer by making the charging more convenient.

This result may suggest that, at the launch period, more tax credit to EV purchasing may be not efficient in stimulating the market share of EVs. One possible reason is that the early adopters of EVs have a higher wage income comparing to average vehicle consumers. Thus they are less price sensitive and concern more about other characteristics of the vehicle, such as the environmental impact or the driving experience.

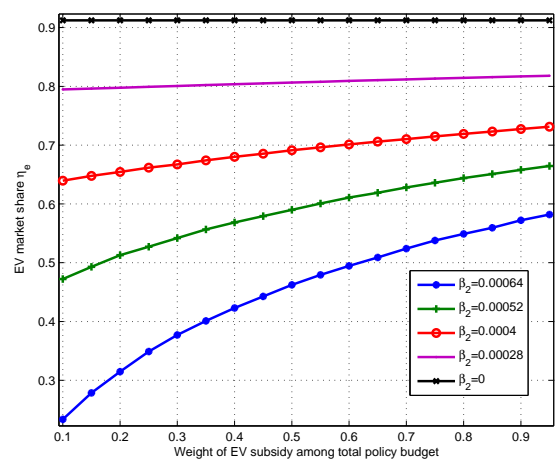

(a) EV market share vs. subsidy weight.

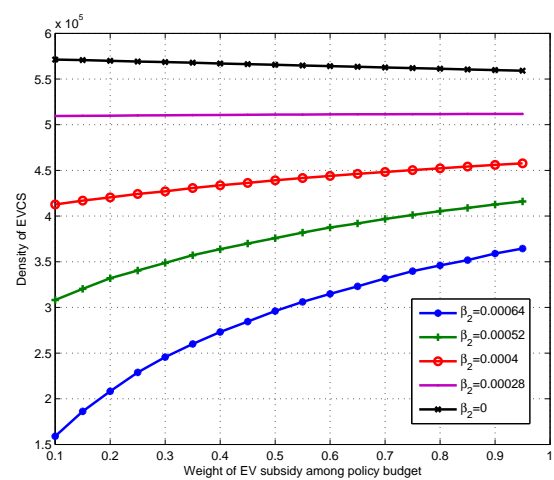

(b) Density of EVCSs vs. subsidy weight.

Figure 6: Subsidy effect with different coefficients

\subsection{Socially optimal solution vs. private market solution}

In Section 4.4, the analytical result shows the socially optimal solution requires to invest in more charging facilities than that from the private market solution. In this section, a numerical result is presented to illustrate this difference in the EVCS market. In the simulation, we assume that all charging stations have the same favorability rate $f$ and building cost $F$. In the private market setting, the investor simply chooses how many charging stations to invest and determines the optimal charging price to maximize the total profit collected from charging stations defined in (18). In the socially optimal solution, the social planner maximizes the social welfare defined in (19) by determining the number of charging stations.

When the weight of the consumer was small $(\lambda=10)$, the decision of the social planner was close to the outcome of the private market. As shown in Fig. 7(a), the market share of the 


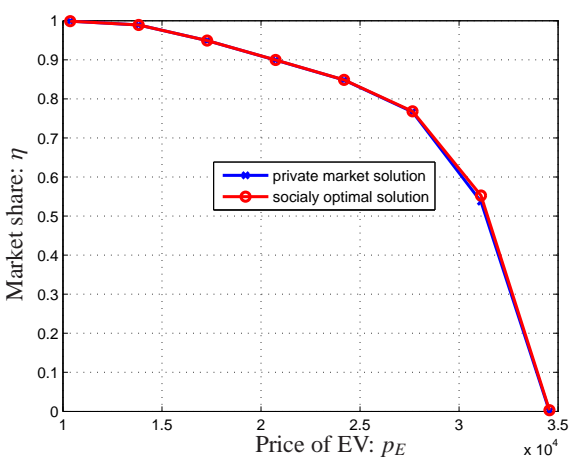

(a) EV market share vs. EV price.

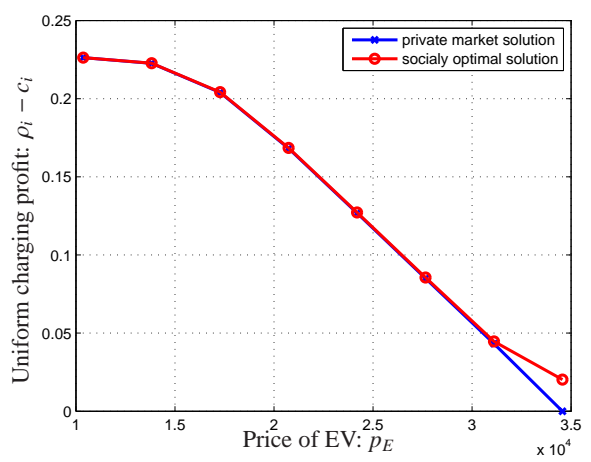

(c) Charging price vs. EV price.

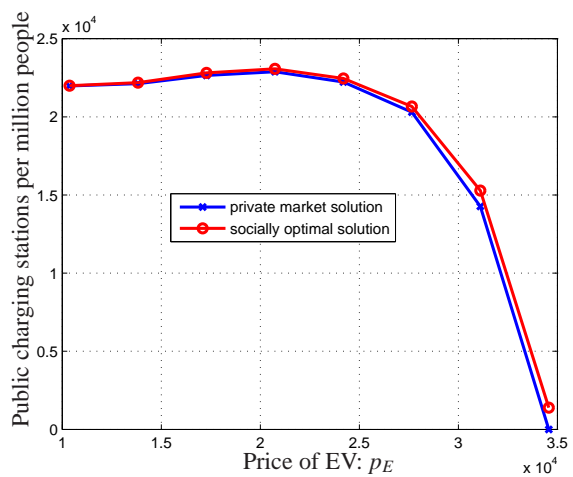

(b) Density of EVCS vs. EV price.

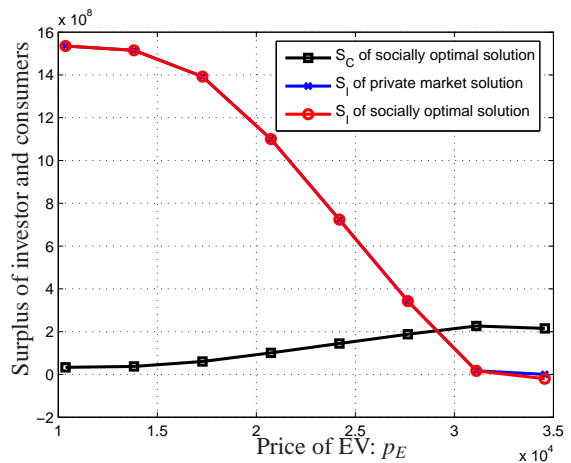

(d) Total profit of building charging stations vs. EV price.

Figure 7: Socially optimal solution vs. private market solution. $p_{G}=\$ 17460$,

$$
\begin{aligned}
& N_{c}=10^{6}, F=\$ 15000, f=0.001, c=0.08 \$ / \mathrm{mile}, \alpha_{1}=10, \alpha_{2}=25, \\
& \beta_{1}=2, \beta_{2}=7 \times 10^{-4}, \lambda=10 .
\end{aligned}
$$

socially optimal solution was slightly greater than the private market solution. We observed that when $p_{E}=\$ 34570$, the investor would not invest in any charging stations due to the neglectful market share of EVs. The uniform unit charging profit of the private market solution was also decreasing as the price of EV increased. This could be explained by (14) where the profit was decreasing when the market share $\eta$ shrinked. The result of the socially optimal solution was close to the private market outcome except when the price of EV was high $\left(p_{E}=\$ 34500\right)$. In this case, the investor had no motivation to invest in any charging stations due to the neglectful market share of EVs. However, the social planner would still build some charging stations taking into account of the utilities of EV consumers. As shown in Fig. $7(\mathrm{~d})$, when the EV price was low, the total operation profit from charging stations dominated the consumer surplus. As the price of EV raised, the profit dropped sharply due to the shrink of the EV market share. However, as the price of EV increased, the charging cost droped, as shown in Fig. 7(c), and raised the charging utility and the consumer surplus. When the profit dropped below the consumer surplus, the social planner mainly focused on the consumers and built charging stations even when the 
total charging profit was negative.

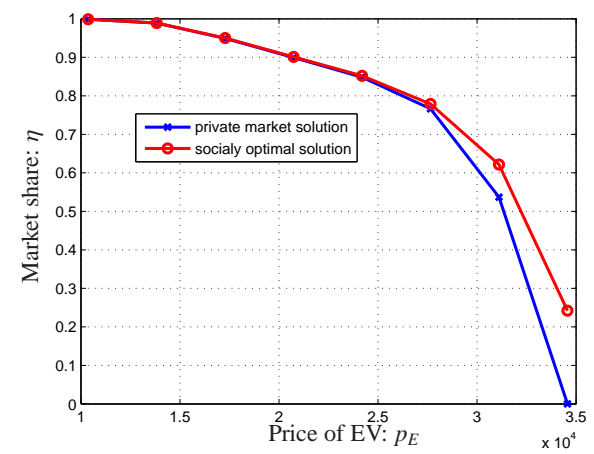

(a) EV market share vs. EV price.

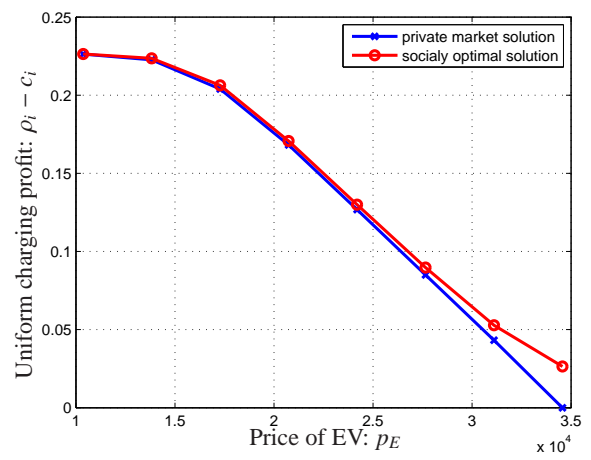

(c) Charging price vs. EV price.

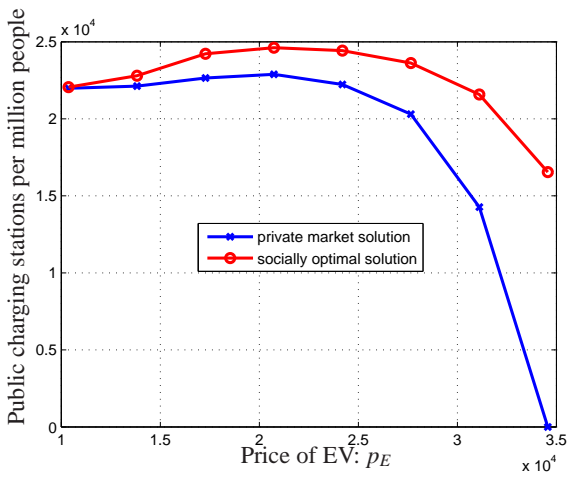

(b) Density of EVCS vs. EV price.

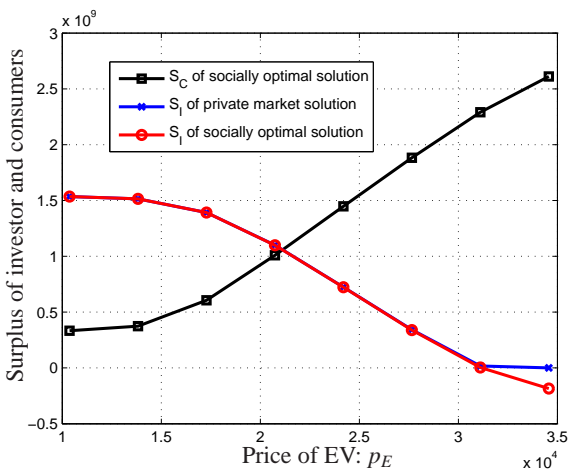

(d) Total profit of building charging stations vs. EV price.

Figure 8: Socially optimal solution vs. private market solution. $p_{G}=\$ 17460$,

$N_{c}=10^{6}, F=\$ 15000, f=0.001, c=0.08 \$ / \mathrm{mile}, \alpha_{1}=10, \alpha_{2}=25$, $\beta_{1}=2, \beta_{2}=7 \times 10^{-4}, \lambda=100$.

As shown in Fig. 8 , when the weight of consumer surplus was larger $(\lambda=100)$, the socially optimal solution deviated from the private market outcome significantly, especially when the EV price was high. The market share of EV, the density of charging services and the unit charging profit of the socially optimal solution were larger than the ones of the private market outcome. This could be explained by Fig. 8(d) When $p_{E}$ was low, the consumer surplus was comparable to the profit of charging stations and social planner biased to consumers notably. When $p_{E}$ was high, the profit went to negative and was dominated by the consumer surplus. The social planner's decision deviated from the private market outcome significantly.

The simulation result suggests that, bringing down the cost of EVs makes all parties benefited. The investors of charging station build more charging services and earn more profit with lower EV prices. The consumers face attractive EV price and have more charging options which eliminates the anxiety of driving range. Moreover, the private market outcomes is closer to the socially optimal solution as the price of EV decreases. 
When the EV price is not low enough and the private market solution deviates the socially optimal solution, it is reasonable to supply subsidy to the EV purchase. Meanwhile, subsidies to charging stations or other policies can also fill the gap between the private market outcomes and the socially efficient solution.

\subsection{Other policies}

Beyond the subsidy policy, the proposed model can be directly used to study other policies, such as regulations. The government may require a minimal share of EVs in the vehicle fleet (Winebrake and Farrell, 1997) such as the Zero Emission Vehicle program in California. This could stimulate the EV market and attract more investment on the EV charging station via the feedback loop between the EV and EVCS market. The impact of this kind of policy can be estimated by adding an external shock to the EV market and simulating the result in the EVCS market. Similarly, the government may mandate the minimal number of EV charging stations in public parking lots as being recently adopted the Beijing municipal government.

Another approach is to allow the EV charging operator to participant in the operation of the power system, not just a price taker. By doing so, the operator of the charging stations may adjust the EV charging profile according to the requirement from the power system operator to make the grid more reliable and efficient. These vehicle to grid (V2G) services typically include spinning reserves, frequency regulation and peak power supply (Kempton and Tomić, 2005; Lund and Kempton, 2008; Guille and Gross, 2009; Sovacool and Hirsh, 2009).

The option to participate in the power market may attract more investment in charging stations. The charging cost would be lower not only due to the competition between charging stations, but also the income from the V2G services. In this case, the social planner has more motivation to help the successful launch of EVs and support more charging stations, since the adoption of EVs not only generates environmental benefits but also help the grid to be cleaner, more robust and more efficient. The EV owners will enjoy cheaper charging prices and other consumers have cleaner energy. Everybody wins.

To model the impact of the adoption of the V2G services, the decision model of the investor needs to be extended. When making the investment decision, the investor needs to consider not only the charging profit but also the V2G revenue. One possible way is to add one more term in the profit function $\Pi$ to indicate the $\mathrm{V} 2 \mathrm{G}$ income as a function of the EV charging population. When operating the charging stations, the charging price is designed to maximize the total profit from EV charging and V2G services. The density of EV charging stations are expected to increase from the result of the case without $\mathrm{V} 2 \mathrm{G}$ options. The profit of investors and consumer surplus are expected to increase as well.

\subsection{Potential application and future work}

In this work, we considered the two-sided EV market in a homogenous setting. The charging rate of the stations is assumed uniform and the market across areas are indifferent. In this subsection, we will discuss several directions for future research, including the EV market under heterogeneous settings, and how our models can be helpful to understand the market outcome.

One possible direction is to incorporate the choices of different types of charging station technology in the decision model. The charging time of different charging rate varies dramatically, which affects the consumer choice of charging stations, and the capital cost differs greatly, which has an influence on the investment decisions. The deployment of all three levels of charging was considered in Luo et al. (2015) where a sequential deployment of charging stations with various 
charging rate was simulated. To consider the option of choosing charging rate in our model, we can add one more variable to indicate the charging level of the charging station in the investor decision model of EV charging stations. In the consumer choice model, the waiting time can be included in the utility function as part of the charging cost. In this case, the attractions and capital cost of EV charging stations with various charging levels are different and the investor's decision is more complicated.

Besides the different charging technologies, we can evaluate different policy impacts in heterogeneous markets. In different locations, the environmental benefit of EVs are different and the policies may also vary. In areas where a large share of electricity is generated from renewables or hydro, the environmental benefits would be higher while in areas with a large share of coalfired power generation, the environmental impact of EVs could even be negative. To incorporate this heterogeneity, we could include the environmental benefits of EV adoption in the objective function of social planner's decision in equation (19) and solve the social planner's problems in different locations individually. Recognizing this heterogeneity, the government policies could vary across locations in order to achieve the spatially-variant optimal level of EV adoption.

\section{Conclusion}

In this paper, the two-sided market problem of EV-EVCS is considered. A sequential game is formulated to analyze the indirect network effects between the charging station investor and consumers. The optimal operation decision of charging stations is shown as locational equal profit pricing. An asymptotic optimal algorithm of investment decision is proposed which reduces the computation complexity significantly. The social welfare optimization is discussed and it is shown that the socially optimal solution requires more charging stations than the market outcomes. The numerical results are presented to illustrate the impact of government subsidy policy and the difference between the private market solution and the socially optimal solution.

As an analytical approach to understanding the market dynamics of EV diffusion, this paper assumes a stylized model for both the consumers and the investor. Here we aim to capture major factors in the interactions between the consumers and the investor, including the EV price, the coverage of the charging stations, and the price of charging. Ignored in the model includes several nontrivial and practically significant factors. For instance, the price of EV is assumed exogenous, and the EV consumers and charging stations are mostly homogeneous (except that the favorability rating, the operating cost, and pricing of charging are different across locations). A multi-stage counter part of this work is to be reported in the future.

\section{Appendix A. Proof}

Here the proofs under the assumption of the type I extreme value vehicle preference distribution are presented. The uniform preference distribution proof can be found in Yu et al. (2014). The subscript $j$ is dropped in this section for convenience.

\section{Appendix A.1. Proof of Theorem 3}

In Theorem 2, the optimal charging price is shown to generate uniform profits across charging stations. Denote the uniform profit by $r \triangleq \rho_{i}^{*}-c_{i}$, the sum of the exponential systematic utility 
by $v=\sum_{i=1}^{N_{E}} v_{i}=\sum_{i=1}^{N_{E}} \exp \left(\alpha_{1} f_{i}-\alpha_{2} c_{i}\right)$ and the ratio of the utility and the exponential profit by $\kappa=v / \exp \left(\alpha_{2} r\right)$. Equation (14) can be rewritten as

$$
\begin{aligned}
g(v, r) & \triangleq \alpha_{2} \beta_{1} r(1-\eta)\left(1-P_{0}\right)+\alpha_{2} r P_{0}-1 \\
& =\beta_{1} \ln (v / \kappa) \frac{C}{\left(q_{0}+\kappa\right)^{\beta_{1}}+C} \frac{\kappa}{q_{0}+\kappa}+\ln (v / \kappa) \frac{q_{0}}{q_{0}+\kappa}-1 \\
& =0,
\end{aligned}
$$

(Appendix A.1)

where $C=e^{\left(\beta_{1} \mathbb{E}\left(U_{G}\right)-\beta_{2} p_{G}+\beta_{G} p_{E}\right)}$ and $q_{0}=e^{\left(\alpha_{1} f_{0}-\alpha_{2} \rho_{0}\right)}$.

Note the first term in the left hand side of Appendix A.1,$\alpha_{2} \beta_{1} r(1-\eta)\left(1-P_{0}\right)$, is positive. We can conclude that as $v \rightarrow+\infty, \kappa \rightarrow+\infty$. Otherwise, the second term $\ln (v / \kappa) \frac{q_{0}}{q_{0}+\kappa} \rightarrow+\infty$ which violates Appendix A.1.

As the sum of exponential systematic utility $v$ increases, the charging service at the EVCSs is more convenient, thus more consumers tend to purchase EVs and prefer to charge at the public charging stations. $\kappa \rightarrow+\infty$ gives the convergence of the market share $\eta$ and $P_{0}$, which is stated as follows.

Lemma 1.

$$
\begin{array}{ll}
\lim _{v \rightarrow+\infty} \eta=\lim _{v \rightarrow+\infty} \frac{\left(q_{0}+\kappa\right)^{\beta_{1}}}{\left(q_{0}+\kappa\right)^{\beta_{1}}+C} & =1 \\
\lim _{v \rightarrow+\infty} P_{0}=\lim _{v \rightarrow+\infty} \frac{q_{0}}{q_{0}+\kappa} & =0 .
\end{array}
$$

(Appendix A.2)

Proof. Since $q_{0}$ and $C$ are constant, $\beta_{1}>0$ and $\kappa \rightarrow+\infty, \eta \rightarrow 1$ and $P_{0} \rightarrow 0$.

A direct result of Lemma 1 is that the uniform profit $r \rightarrow+\infty$ as $v \rightarrow+\infty$. Otherwise Appendix A.1 does not hold any more.

By applying the implicit function theorem (IFT) to function $g(v, r)$, we get the derivative of profit $r$ with respect to the exponential systematic utility $v$,

$$
\frac{\partial r}{\partial v}=-\frac{\partial g(v, r) / \partial v}{\partial g(v, r) / \partial r}=\frac{1}{\alpha_{2} v} \frac{1}{1+h},
$$

(Appendix A.3)

where

$$
h=\frac{\beta_{1}(1-\eta)\left(1-P_{0}\right)+P_{0}}{\alpha_{2} \beta_{1}^{2} r \eta(1-\eta)\left(1-P_{0}\right)^{2}-\alpha_{2} \beta_{1} r(1-\eta) P_{0}\left(1-P_{0}\right)+\alpha_{2} r P_{0}\left(1-P_{0}\right)} .
$$

The numerator of $h, \beta_{1}(1-\eta)\left(1-P_{0}\right)+P_{0}$, converges to 0 as $v \rightarrow+\infty$. Denote the denominator of $h$ by $H$. If $\beta_{1}>1, H$ can be rewritten as

$$
\begin{aligned}
H= & \alpha_{2} \beta_{1} r(1-\eta)\left(1-P_{0}\right)\left(1-P_{0}\right)+\alpha_{2} r P_{0}\left(1-P_{0}\right) \\
& +\alpha_{2} \beta_{1} r(1-\eta)\left(1-P_{0}\right)\left[\beta_{1} \eta\left(1-P_{0}\right)-1\right] \\
= & \left(1-P_{0}\right)+\alpha_{2} \beta_{1} r(1-\eta)\left(1-P_{0}\right)\left[\beta_{1} \eta\left(1-P_{0}\right)-1\right],
\end{aligned}
$$

(Appendix A.4)

where the last equality is because of Appendix A.1. In Appendix A.4, the first term converges to 1 and the second term is positive as $v \rightarrow+\infty$.

If $\beta_{1} \leq 1, H$ can be rewritten as

$$
\begin{aligned}
H= & \alpha_{2} \beta_{1} r(1-\eta)\left(1-P_{0}\right)\left[\beta_{1} \eta\left(1-P_{0}\right)-P_{0}\right] \\
& +\alpha_{2} r P_{0}\left[\beta_{1} \eta\left(1-P_{0}\right)-P_{0}\right]+\alpha_{2} r P_{0}\left[1-\beta_{1} \eta\left(1-P_{0}\right)\right] \\
= & {\left[\beta_{1} \eta\left(1-P_{0}\right)-P_{0}\right]+\alpha_{2} r P_{0}\left[1-\beta_{1} \eta\left(1-P_{0}\right)\right], }
\end{aligned}
$$

(Appendix A.5)

where the last equality is because of Appendix A.1p. In Appendix A.5, the first term converges to $\beta_{1}$ as $v \rightarrow+\infty$ and the second term is positive. 
In both cases, $H$ is bounded below from zero as $v \rightarrow+\infty$. Thus $h \rightarrow 0$ and $v \frac{\partial r}{\partial v} \rightarrow \frac{1}{\alpha_{2}}$ in Appendix A.3.

By the l'Hôpital's rule, since $r \rightarrow+\infty$ as $v \rightarrow+\infty$,

$$
\lim _{v \rightarrow+\infty} \frac{r}{\ln v}=\lim _{v \rightarrow+\infty} \frac{\partial r / \partial v}{1 / v}=\lim _{v \rightarrow+\infty} \frac{\partial^{2} r / \partial v^{2}}{-v^{-2}}=\frac{1}{\alpha_{2}},
$$

(Appendix A.6)

which completes the proof.

Note when $v>\bar{v}_{1}$ for some $\bar{v}_{1}>0, h>0 . r(v)$ is strictly increasing in $v$ and $v \frac{\partial r}{\partial v}<\frac{1}{\alpha_{2}}$ when $v>\bar{v}_{1}$.

\section{Appendix A.2. Proof of Theorem 4}

First, fixing the number of charging stations to build as $N_{E}$, we examine where to build these stations. Denote the sum of exponential systematic utility by $v=\sum_{i=1}^{N_{E}} v_{i}$ and the uniform charging profit by $r=\rho_{i}^{*}-c_{i}$. The unit operational profit of the investor can be stated as

$$
\frac{\Pi(v)}{N_{c} D}=r(v) \eta(v) \sum_{i=1}^{N_{E}} P_{i}(v)=r(v) \frac{\left[q_{0}+\kappa(v)\right]^{\beta_{1}}}{\left[q_{0}+\kappa(v)\right]^{\beta_{1}}+C} \frac{\kappa(v)}{q_{0}+\kappa(v)},
$$

(Appendix A.7)

where $q_{0}=\exp \left(\alpha_{1} f_{1}-\alpha_{2} \rho_{0}\right), \kappa(v)=v \exp \left(-\alpha_{2} r\right)$, and $C=\exp \left(\beta_{1} \mathbb{E}\left(U_{G}\right)-\beta_{2} p_{G}+\beta_{G} p_{E}\right)$. The derivative of $k(v)$ with respect to $v$ is stated as

$$
\frac{\partial \kappa(v)}{\partial v}=\exp \left(-\alpha_{2} r\right)\left(1-\alpha_{2} v \frac{\partial r}{\partial v}\right)
$$

(Appendix A.8)

which is strictly positive when $v>\bar{v}_{1}$ according to the discussion in Sec. Appendix A.1. So the operational profit $\Pi(v)$ is strictly increasing in $v$ when $v>\bar{v}_{1}$.

The second order derivative of $\Pi(v)$ with respect to $v$ is stated as

$$
\begin{aligned}
\frac{1}{N_{c} D} \frac{\partial^{2} \Pi}{\partial v^{2}}= & \frac{\eta}{v^{2}}\left\{v^{2} \frac{\partial^{2} r}{\partial v^{2}}\left(1-P_{0}\right)\right. \\
& +\left(-2 r P_{0}\right)\left(1-P_{0}\right)^{2} \\
& +\frac{2}{\alpha_{2}} \frac{1}{1+h}\left(1-P_{0}\right)\left[(1-\eta) \beta_{1}\left(1-P_{0}\right)+P_{0}\right] \\
& \left.+r(1-\eta) \beta_{1}\left(1-P_{0}\right)^{2}\left[\beta_{1}\left(1-2 \eta-P_{0}\right)+(2 \eta+3) P_{0}-1\right]\right\} .
\end{aligned}
$$

As $v \rightarrow+\infty, v^{2} \frac{\partial^{2} r}{\partial v^{2}} \rightarrow-\frac{1}{\alpha_{2}}, \eta \rightarrow+\infty$ and $P_{0} \rightarrow 0$. So when $v>\bar{v}_{2}$ for some $\bar{v}_{2}>0$, the first term in Appendix A.9 is negative and bounded above from zero. The second and last term are negative. The third term is positive but converging to zero. The second order derivative of $\Pi(v)$ is negative and we have the concavity of $\Pi(v)$ stated in the following lemma.

Lemma 2. Asymptotically, $\Pi(v)$ is an increasing and concave function of $v$.

The monotonicity of $\Pi(v)$ implies that, if given two station candidates $j$ and $j^{\prime}$, fixing the other $\left(N_{E}-1\right)$ stations, the one with larger $v_{i}=\exp \left(\alpha_{1} f_{i}-\alpha_{2} c_{i}\right), i \in\left\{j, j^{\prime}\right\}$ should be built because the building costs are the same. So we have the optimal strategy about where to build stations as follows.

Lemma 3. Fixing the number of stations to build as $N_{E}$, the asymptotically optimal strategy of building is to pick $N_{E}$ candidates with largest $v_{i}=\exp \left(\alpha_{1} f_{i}-\alpha_{2} c_{i}\right)$. 
Next, after we sort the $N_{L}$ candidate locations by $v_{i}$, we can present the cost $\sum_{i=1}^{N_{E}} F\left(s_{i}\right)=$ $(1+\gamma) F_{0} N_{E}$ as a function of $v=\sum_{i=1}^{N_{E}} v_{i}$. We can treat $v$ as a continuous variable and write $\tilde{F}(v) \triangleq$ $(1+\gamma) F_{0} N_{E}$ as $\tilde{F}(v)=(1+\gamma) F_{0} N+\left(v-\sum_{i=1}^{N} v_{i}\right)(1+\gamma) F_{0} / v_{N+1}$, if $\sum_{i=1}^{N} v_{i}<v \leq \sum_{i=1}^{N+1} v_{i}$. Since $v_{i} \geq v_{i+1}$, the cost $\tilde{F}(v)$ is a piece wise linear convex function of $v$. The partial derivative $\partial \tilde{F}(v) / \partial v$ is piece wise constant and increasing in $v$.

The trends of $\Pi(v), \tilde{F}(v)$ and the derivatives are plotted in Fig. A.9 and Fig. A.10 In Fig. A.9, $v^{*}$ is the optimal point to maximize the profit $(\Pi(v)-\tilde{F}(v))$. Fig. A.10 shows the derivative of $\tilde{F}(v)$ is increasing and the marginal profit $\frac{\partial \Pi(v)}{\partial v}$ is decreasing when $v$ is large enough. The last cross point of the derivatives of $\Pi(v)$ and $\tilde{F}(v)$ is the optimal point. Combining Lemma2 and 3 , we have the asymptotic optimality.

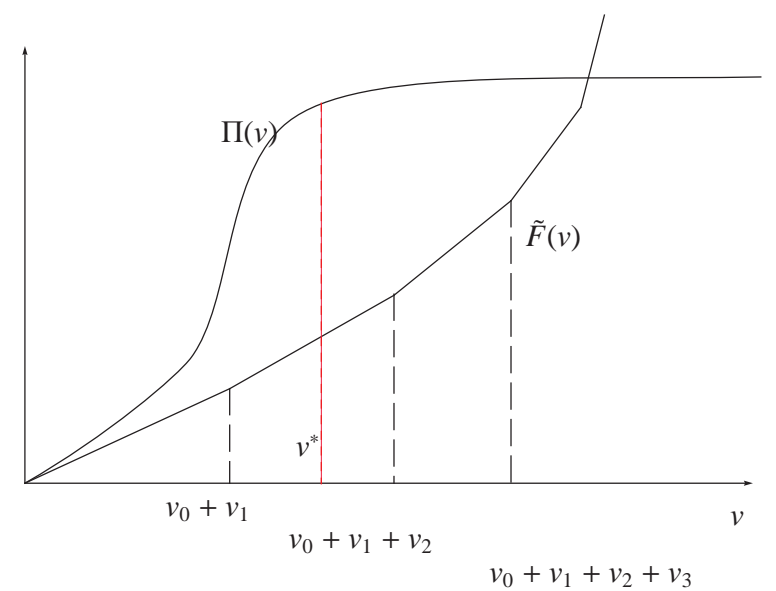

Figure A.9: Profit and cost of charging stations.

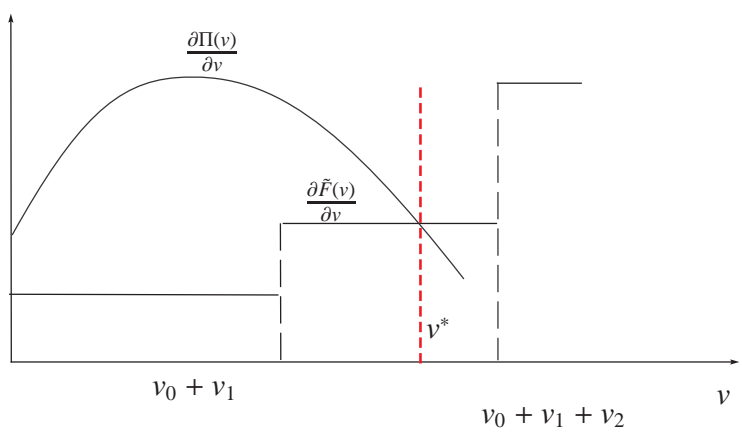

Figure A.10: Profit and cost derivatives of charging stations. 


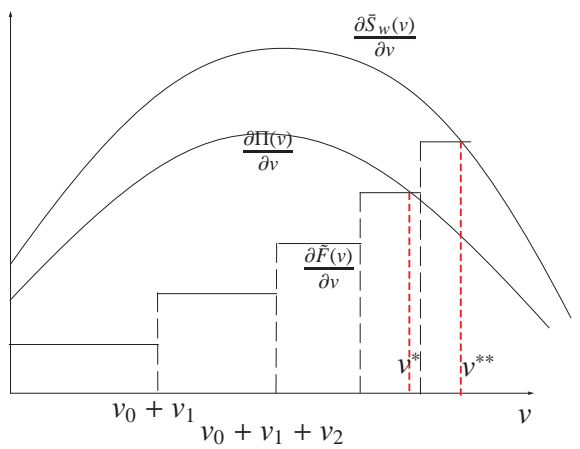

Figure A.11: Derivatives of social welfare and investor utility.

\section{Appendix A.3. Proof of Theorem 5}

Denote the sum of consumer utility and investor's operational profit by $\bar{S}_{W}(v)=\lambda N_{C} S_{C}(v)+$ $\Pi(v)$, the social planner is maximizing $\left(\bar{S}_{W}(v)-\tilde{F}(v)\right)$.

The consumer utility, $S_{C}(v)$, can be rewritten as a function of the total exponential systematic utility $v$ as follows.

$$
S_{C}(v)=\ln \left[\left(q_{0}+v \exp \left(-\alpha_{2} r\right)\right)^{\beta_{1}} C_{1}+C_{2}\right],
$$

which is increasing in $v$. So

$$
\frac{\partial \bar{S}_{W}(v)}{\partial v}=\lambda N_{C} \frac{\partial S_{C}(v)}{\partial v}+\frac{\partial \Pi(v)}{\partial v}>\frac{\partial \Pi(v)}{\partial v} .
$$

We plot the derivative of the social welfare as well as that of the investor utility in Fig A.11 The optimal social welfare point $v^{* *}$ is also the cross point of $\frac{\partial \tilde{F}(v)}{\partial v}$ and $\frac{\partial \bar{S}_{W}(v)}{\partial v}$. Since $\frac{\partial \bar{S}_{W}(v)}{\partial v}>\frac{\partial \Pi(v)}{\partial v}$, it is always true that $v^{* *} \geq v^{*}$, which implies the socially optimal solution requires more charging stations than the private market outcomes.

\section{Acknowledgement}

This work is supported in part by the National Science Foundation under Grant CNS-1248079.

\section{References}

Anderson, S. T., Kellogg, R., Sallee, J. M., 2013. What do consumers believe about future gasoline prices? Journal of Environmental Economics and Management 66 (3), 383-403.

Armstrong, M., Wright, J., 2007. Two-sided markets, competitive bottlenecks and exclusive contracts. Economic Theory 32 (2), 353-380.

Arthur, W. B., 1989. Competing technologies, increasing returns, and lock-in by historical events. The economic journal 99 (394), 116-131.

Beresteanu, A., Li, S., 2011. Gasoline prices, government support, and the demand for hybrid vehicles in the United States*. International Economic Review 52 (1), 161-182.

Bernardo, V., Borrell, J. R., Perdiguero, J., 2013. Fast charging stations: Network planning versus free entry. 
Bloomberg New Energy Finance, 2016. Electric vehicles to be 35\% of global new car sales by 2040. Available from: http://www.prnewswire.com/news-releases/electric-vehicles-to-be-35-of-global-newcar-sales-by-2040-300225689.html.

Bresnahan, T. F., Greenstein, S., 1999. Technological competition and the structure of the computer industry. The Journal of Industrial Economics 47 (1), 1-40.

Bunch, D. S., Bradley, M., Golob, T. F., Kitamura, R., Occhiuzzo, G. P., 1993. Demand for clean-fuel vehicles in california: a discrete-choice stated preference pilot project. Transportation research: part A 27A (3), 237-253.

Caillaud, B., Jullien, B., 2003. Chicken \& egg: competition among intermediation service providers. Rand Journal of Economics 34 (2), 309-328.

Chen, S., Mount, T., Tong, L., January 2013a. Optimizing operations for large scale charging of electric vehicles. In: Proceedings of the 46th Hawaii International Conference on System Sciences. Wailea, HI, USA, pp. 2319-2326.

Chen, S., Tong, L., November 2012. iEMS for large scale charging of electric vehicles: Architecture and optimal online scheduling. In: Proceedings of IEEE Third International Conference on Smart Grid Communications. Tainan, Taiwan, pp. 629-634.

Chen, T. D., Kockelman, K. M., Khan, M., January 2013b. The electric vehicle charging station location problem: A parking-based assignment method for seattle. In: Proceedings of the 92nd Annual Meeting of the Transpotation Research Board in Whasington DC.

Clements, M. T., Ohashi, H., 2005. Indirect network effects and the product cycle: Video games in the U.S., 1994-2002. The Journal of Industrial Economics 53 (4), 515-542.

Corts, K. S., Lederman, M., 2009. Software exclusivity and the scope of indirect network effects in the U.S. home video game market. international Journal of industrial Organization 27 (2), 121-136.

Delang, C. O., Cheng, W.-T., 2012. Consumers' attitudes towards electric cars: A case study of Hong Kong. Transportation Research Part D: Transport and Environment 17 (6), 492-494.

Dubé, J. P. H., Hitsch, G. J., Chintagunta, P. K., 2010. Tipping and concentration in markets with indirect network effects. Marketing Science 29 (2), 216-249.

Economides, N., 1996. The economics of networks. International journal of industrial organization 14 (6), 673-699.

Electric Power Reserach Institute, 2013. Total cost of ownership model for current plug-in electric vehicles. Tech. rep., available from: http://www.epri.com/abstracts/Pages/ProductAbstract.aspx? Product Id $=000000003002001728$.

Electric Transportation Engineering Corporation, 2013. Electric vehicle public charging-time vs. energy. Available from: http://www. theevproject. com/cms-assets/documents/106078-254667.tvse.pdf.

Ewing, G. O., Sarigöllü, E., 1998. Car fuel-type choice under travel demand management and economic incentives. Transportation Research Part D: Transport and Environment 3 (6), 429-444.

Farrell, J., Saloner, G., 2003. Standardization, ompatibility, and innovation. Rand Journal of Economics 34 (2), 309-328.

Frade, I., Riberiro, A., Goncalves, G., Antunes, A. P., 2011. Optimal location of charging stations for electric vehicles in a neighbornood in Lisbon, Portugal. Transportation Research Record: Journal of the Transportation Research Board 2252, 91-98.

Gallagher, K. S., Muehlegger, E., 2011. Giving green to get green? Incentives and consumer adoption of hybrid vehicle technology. Journal of Environmental Economics and Management 61 (1), 1-15.

Gandal, N., Kende, M., Rob, R., 2000. The dynamics of technological adoption in hardware/software systems: The case of compact disc players. RAND Journal of Economics 31, 43-61.

Gao, H. O., Kitirattragarn, V., 2008. Taxi owners' buying preference of hybrid-electric vehicles and their implications for emissions in New York City. Transportation research: part A 42, 1064-1073.

Green Retail Decisions, 2011. Walmart to install EV charging stations. Available from: http://www. greenretaildecisions. com/news/2011/12/01/walmart-to-install-ev-charging-stations-

Green Retail Decisions, 2012. Kohl's expands electric vehicle charging stations. Available from: http://www. greenretaildecisions. com/news/2012/09/06/kohls-expands-electric-vehicle-chargingstations.

Green Retail Decisions, 2013. Kroger expands EV charging station network. Available from: http://www. greenretaildecisions. com/news/2013/04/11/kroger-expands-ev-charging-station-network.

Guille, C., Gross, G., 2009. A conceptual framework for the vehicle-to-grid (v2g) implementation. Energy policy 37 (11), 4379-4390.

Hackbarth, A., Madlener, R., 2013. Consumer preferences for alternative fuel vehicles: A discrete choice analysis. Transportation Research Part D: Transport and Environment 25, 5-17.

He, F., Wu, D., Yin, Y., Guan, Y., Jan. 2013. Optimal deployment of public charging stations for plug-in hybrid electric vehicles. Tansportation Research Part B: Methodological 47, 87-101.

He, L., Chen, W., Conzelmann, G., 2012. Impact of vehicle usage on consumer choice of hybrid electric vehicles. Transportation Research Part D: Transport and Environment 17 (3), 208-214.

Hotelling, H., 1990. Stability in competition. Springer. 
Hybridcars, 2014. 2011-2014 plug-in vehicles monthly sales dashboard. Available from: http://www.hybridcars . com/december-2014-dashboard/.

Jaffe, A. B., Stavins, R. N., 1994. The energy paradox and the diffusion of conservation technology. Resource and Energy Economics 16 (2), 91-122.

Josh Agenbroad and Ben Holland, 2014. Pulling back the veil on ev charging station costs. Available from: http:// blog.rmi.org/blog_2014_04_29_pulling_back_the_veil_on_ev_charging_station_costs.

Kahn, M. E., 2007. Do greens drive hummers or hybrids? Environmental ideology as a determinant of consumer choice. Journal of Environmental Economics and Management 54 (2), 129-145.

Kahn, M. E., Vaughn, R. K., 2009. Green market geography: The spatial clustering of hybrid vehicles and leed registered buildings. The BE Journal of Economic Analysis \& Policy 9 (2).

Katz, M. L., Shapiro, C., 1985. Network externalities, competition, and compatibility. The American Economic Review 75 (3), 424-440.

Kempton, W., Tomić, J., 2005. Vehicle-to-grid power fundamentals: Calculating capacity and net revenue. Journal of power sources 144 (1), 268-279.

Kurani, K. S., Turrentine, T., Sperling, D., 1996. Testing electric vehicle demand in hybrid households using a reflexive survey. Transportation Research Part D: Transport and Environment 1 (2), 131-150.

Lebeau, K., Mierlo, J. V., Lebeau, P., Mairesse, O., Macharis, C., 2012. The market potential for plug-in hybrid and battery electric vehicles in flanders: A choice-based conjoint analysis. Transportation Research Part D: Transport and Environment 17, 592-597.

Li, S., Tong, L., Xing, J., Zhou, Y., 2014. The market for electric vehicles: indirect network effects and policy impacts. Available from: http://papers.ssrn.com/sol3/papers.cfm?abstract_id=2515037.

Loveday, E., 2014. Beijing passes massive charging station mandate 1000 DC quick chargers by end of 2014 Available from: http://insideevs.com/beijing-passes-massive-charging-station-mandate-1000dc-quick-chargers-end-2014/.

Lund, H., Kempton, W., 2008. Integration of renewable energy into the transport and electricity sectors through V2G Energy Policy 36 (9), 3578-3587.

Luo, C., Huang, Y.-F., Gupta, V., 2015. A consumer behavior based approach to multi-stage ev charging station placement. In: IEEE 81st Vehicular Technology Conference (VTC Spring). IEEE, pp. 1-6.

Marschak, J., 1960. Binary-choice constraints and random utility indicators. In: Proceedings of a Symposium on Mathematical Methods in the Social Sciences. Vol. 7. pp. 19-38.

McFadden, D., 1974. Conditional logit analysis of qualitative choice behavior. Academic Press.

McKinsey\&Company, 2012. Profiling Japan's early EV adopters. Tech. rep., available from: http://www . mckinseyonmarketingandsales.com/sites/default/files/pdf/Japan_electric_car_consumers . pdf.

Meyer, P. E., Winebrake, J. J., 2009. Modeling technology diffusion of complementary goods: The case of hydrogen vehicles and refueling infrastructure. Technovation 29 (2), 77-91.

Pinkse, J., Slade, M. E., Brett, C., 2002. Spatial price competition: a semiparametric approach. Econometrica 70 (3), 1111-1153.

Potoglou, D., Kanaroglou, P. S., 2007. Household demand and willingness to pay for clean vehicles. Transportation Research Part D: Transport and Environment 12 (4), 264-274.

Rochet, J., Tirole, J., 2004. Two-sided markets: an overview. IDEI working paper, Available from: http://web.mit . edu/14.271/www/rochet_tirole.pdf.

Rohlfs, J., 1974. A theory of interdependent demand for a communications service. The Bell Journal of Economics and Management Science, 16-37.

Rysman, M., 2004. Competition between networks: A study of the market for yellow pages. The Review of Economic Studies 71 (2), 483-512.

Sallee, J. M., 2011. The surprising incidence of tax credits for the Toyota Prius. American Economic Journal: Economic Policy, 189-219.

Salop, S. C., 1979. Monopolistic competition with outside goods. The Bell Journal of Economics, 141-156.

Sexton, S. E., Sexton, A. L., 2014. Conspicuous conservation: The prius halo and willingness to pay for environmental bona fides. Journal of Environmental Economics and Management 67 (3), 303-317.

Shao-yun, G., Liang, F., Hong, L., Long, W., 2012. The planning of electric vehicle charging stations in the urban area. In: 2nd International Conference on Electronic \& Mechanical Engineering and Information Technology (EMEIT).

Sovacool, B. K., Hirsh, R. F., 2009. Beyond batteries: An examination of the benefits and barriers to plug-in hybrid electric vehicles (phevs) and a vehicle-to-grid (v2g) transition. Energy Policy 37 (3), 1095-1103.

U.S. Department of Energy, 2015. Electric vechicle charging station locations. Available from: http://www. afdc . energy.gov/fuels/electricity_locations.html.

Winebrake, J., Farrell, A., 1997. The AFV program and its role in future AFV market development. Transportation Rewsearch Part D 2 (2), 125-132. 
Yu, Z., Li, S., Tong, L., Oct. 2014. On market dynamics of electric vehicle diffusion. In: Proceedings of the 52nd Annual Allerton Conferene on Communication, Control, and Computing. pp. 1051-1057.

Zhou, Y., 2014. Failure to launch in two-sided markets: A study of the US video game market. Working paper. Available from: http://www.docstoc.com/docs/161439721/Failure-to-Launch-in-Two-Sided-MarketsAStudy-of-the-US-Video. 